OPEN ACCESS

Edited by:

Vincent Pialoux

Claude Bernard University Lyon 1

France

Reviewed by:

Nicola Luigi Bragazzi, University of Genoa, Italy

Scott Forbes,

Okanagan College, Canada

*Correspondence:

Nikolai B. Nordsborg nbn@nexs.ku.dk

Specialty section:

This article was submitted to

Exercise Physiology,

a section of the journal

Frontiers in Physiology

Received: 22 December 2016

Accepted: 05 April 2017

Published: 09 May 2017

Citation:

Christensen PM, Shirai Y, Ritz C and Nordsborg NB (2017) Caffeine and Bicarbonate for Speed. A Meta-Analysis of Legal Supplements

Potential for Improving Intense Endurance Exercise Performance.

Front. Physiol. 8:240.

doi: 10.3389/fphys.2017.00240

\section{Caffeine and Bicarbonate for Speed. A Meta-Analysis of Legal Supplements Potential for Improving Intense Endurance Exercise Performance}

\author{
Peter M. Christensen ${ }^{1,2}$, Yusuke Shirai ${ }^{1}$, Christian Ritz ${ }^{1}$ and Nikolai B. Nordsborg ${ }^{1 *}$ \\ 'Section of Integrated Physiology, Department of Nutrition, Exercise and Sports, University of Copenhagen, Copenhagen, \\ Denmark, ${ }^{2}$ Team Danmark, Copenhagen, Denmark
}

A $1 \%$ change in average speed is enough to affect medal rankings in intense Olympic endurance events lasting $\sim 45 \mathrm{~s}$ to 8 min which for example includes $100 \mathrm{~m}$ swimming and $400 \mathrm{~m}$ running ( $\sim \mathrm{min}), 1,500 \mathrm{~m}$ running and $4000 \mathrm{~m}$ track cycling ( $\sim \mathrm{min})$ and 2,000 $\mathrm{m}$ rowing ( $\sim 6-8 \mathrm{~min})$. To maximize the likelihood of winning, athletes utilizes legal supplements with or without scientifically documented beneficial effects on performance. Therefore, a continued systematic evidence based evaluation of the possible ergogenic effects is of high importance. A meta-analysis was conducted with a strict focus on closed-end performance tests in humans in the time domain from $45 \mathrm{~s}$ to $8 \mathrm{~min}$. These test include time-trials or total work done in a given time. This selection criterion results in a high relevance for athletic performance. Only peer-reviewed placebo controlled studies were included. The often applied and potentially ergogenic supplements beta-alanine, bicarbonate, caffeine and nitrate were selected for analysis. Following a systematic search in Pubmed and SportsDiscuss combined with evaluation of cross references a total of 7 (beta-alanine), 25 (bicarbonate), 9 (caffeine), and 5 (nitrate) studies was included in the meta-analysis. For each study, performance was converted to an average speed $(\mathrm{km} / \mathrm{h})$ from which an effect size (ES; Cohens d with 95\% confidence intervals) was calculated. A small effect and significant performance improvement relative to placebo was observed for caffeine (ES: 0.41 [0.15-0.68], $P=0.002$ ) and bicarbonate (ES: 0.40 [0.27-0.54], $P<0.001)$. Trivial and non-significant effects on performance was observed for nitrate (ES: 0.19 [-0.03-0.40], $P=0.09$ ) and beta-alanine (ES: 0.17 [-0.12-0.46], $P=0.24)$. Thus, caffeine's and bicarbonate's ergogenic effect is clearly documented for intense endurance performance. Importantly, for all supplements an individualized approach may improve the ergogenic effect on performance.

Keywords: performance, supplements, ergogenic aids, intense exercise, running, cycling, rowing, swimming 


\section{INTRODUCTION}

A $1 \%$ change in average speed is enough to affect medal rankings in intense Olympic endurance events lasting $\sim 45 \mathrm{~s}$ to $8 \mathrm{~min}$ (Table 1). To maximize the likelihood of winning, athletes utilizes legal supplements with or without scientifically documented effects on performance (Tsitsimpikou et al., 2009; Tscholl et al., 2010; Solheim et al., 2016). Extensive narrative reviews exist, but systematic critical evaluation of frequently used supplements effects on human exercise performance are lacking, but are required in order to advise elite-, subeliteand age-group athletes for or against usage. Importantly, the magnitude of possible performance enhancing effects related to supplementation must be seen relative to the obtainable effects of physical, technical and tactical training. When advising for or against supplement usage it is important to realize that early exposure to supplements may increase the likelihood of reverting to illegal performance enhancing strategies (Dodge and Jaccard, 2006). Moreover, the risk of contamination or undeclared illegal substances in products is noteworthy and can result in a positive doping test (Geyer et al., 2004; Outram and Stewart, 2015). Thus, it is important for athletes and staff to balance the potential performance gain with the known risks associated with supplementation.

In the context of detecting subtle differences in performance the type of exercise testing is of outmost importance. To obtain the highest elite-sport relevance (i.e., high ecologic validity), "closed-end" performance tests with a fixed distance (e.g., 2,000 $\mathrm{m}$ rowing) or duration (e.g., $6 \mathrm{~min}$ maximal rowing) should be the first choice as these resembles competition. However, "open-end" time to exhaustion trials is often applied. This type of evaluation does not resemble athletic competition and likely imposes a high mental stress for the athletes, as there is no set goal. Importantly, closed-end performance tests demonstrate a smaller day to day variance as compared to open-end evaluations (Jeukendrup et al., 1996; Laursen et al., 2007).

The majority of individual Olympic competitions are completed in a time span from $\sim 45 \mathrm{~s}$ to 8 min, including $400 \mathrm{~m}$ running and $100 \mathrm{~m}$ swimming $(\sim 1 \mathrm{~min})$ as well as $4,000 \mathrm{~m}$ cycling $(\sim 4 \mathrm{~min})$ and $2,000 \mathrm{~m}$ rowing $(\sim 7 \mathrm{~min})$ (Table 1 ). Thus, the effect on performance from supplementation in this time domain is of high interest. In previous narrative reviews, beta-alanine and sodium-bicarbonate (termed bicarbonate in the present review) (Stellingwerff et al., 2007) as well as caffeine (Davis and Green, 2009) have been proposed to have an ergogenic potential for such athletic events, and recently nitrate supplementation has received growing attention as a potential ergogenic supplement for athletes (Jones, 2014). Consequently, the present systematic meta-analysis evaluates if supplementation with beta-alanine, bicarbonate, caffeine or nitrate can improve intense endurance exercise performance in the time domain $45 \mathrm{~s}$ to $8 \mathrm{~min}$ when only including closed-end performance tests of high ecological validity.

Currently, a general performance enhancing effect of betaalanine supplementation on intense exercise is suggested based on mixed exercise protocols encompassing primarily time to exhaustion testing (Artioli et al., 2010; Caruso et al., 2012;
Hobson et al., 2012; Quesnele et al., 2014; Trexler et al., 2015). However, a meta-analysis from 2012 including 15 studies with mixed exercise protocols demonstrated no significant effect of supplementation on performance in general, but a separate analysis of 9 mixed performance measures lasting between 60 and $240 \mathrm{~s}$ showed a significant effect (Hobson et al., 2012). A later analysis demonstrated that the effect on open-end exercise testing lasting $0.5-10 \mathrm{~min}$ was almost five times as high as on performance relevant closed-end testing (Saunders et al., 2017). Thus, there is a need to systematically evaluate the effect of beta-alanine supplementation on exercise performance in trained subjects completing performance relevant testing lasting from $45 \mathrm{~s}$ to $8 \mathrm{~min}$.

A number of narrative reviews have addressed the potential ergogenic effect of bicarbonate ingestion (e.g., Requena et al., 2005; McNaughton et al., 2008; Burke, 2013) but meta-analytical approaches have been limited to the effect on running based on only four studies (Schubert and Astorino, 2013) or analyses of different exercise modalities, such as repeated sprinting and time to exhaustion tests (Carr et al., 2011a; Peart et al., 2012). Specifically, a $\sim 2 \%$ increase in 1 min mean power sprinting can be expected based on inference statistics but the effect was not reported to be significant at the $P<0.05$ level (Carr et al., 2011a). Thus, despite conclusions of possible beneficial effects of bicarbonate supplementation for performance the evidence is not convincing and analyses focusing on distinct types of performance tests and time domains are warranted.

Several comprehensive reviews dealing with the potential ergogenic effects of caffeine exist and it is generally acknowledged that ingestion of caffeine can enhance endurance performance lasting 20-250 min (e.g., Graham, 2001; Doherty and Smith, 2004; Ganio et al., 2009; Spriet, 2014,) as well as brief more intense exercise performance lasting 1-3 min (Davis and Green, 2009). However, apart from one review (Ganio et al., 2009) this conclusion is based on a mix of exercise protocols including fixed distance, fixed time or time to exhaustion tests. To the best of our knowledge, only one study has applied a systematic review and meta-analytical approach (Doherty and Smith, 2004) and included various types of exercise tests, resulting in the conclusion that caffeine is less ergogenic during intense short term exercise than longer endurance exercise. Thus, there is a need for a systematic review of caffeines possible ergogenic effects on a single bout of intense exercise lasting $45 \mathrm{~s}$ to $8 \mathrm{~min}$.

A recent area of considerable interest from researchers and athletes is nitrate supplementation via beetroot juice or sodium nitrate ingestion. Based on narrative reviews it has been suggested that nitrate supplementation enhances performance (Clements et al., 2014; Jones, 2014) and a meta-analytical approach revealed that a significant effect exists for time to exhaustion tests whereas the effect on time-trials was insignificant (Hoon et al., 2013). Additionally, a current meta-analysis including a high variety of exercise modalities resulted in an unclear effect (Braakhuis and Hopkins, 2015). Thus, systematic analyses of specific time domains and competition relevant testing are lacking.

The primary aim of the present systematic review is to add to previous primarily narrative reviews by including recent studies with beta-alanine, bicarbonate, caffeine, and nitrate 
TABLE 1 | Event duration and average speed for gold winners at the London 2012 and Rio 2016 Olympics in selected intense endurance events for both male and female athletes and the difference in average speed between silver and gold medalists as well as between number 4 and the bronze medalist.

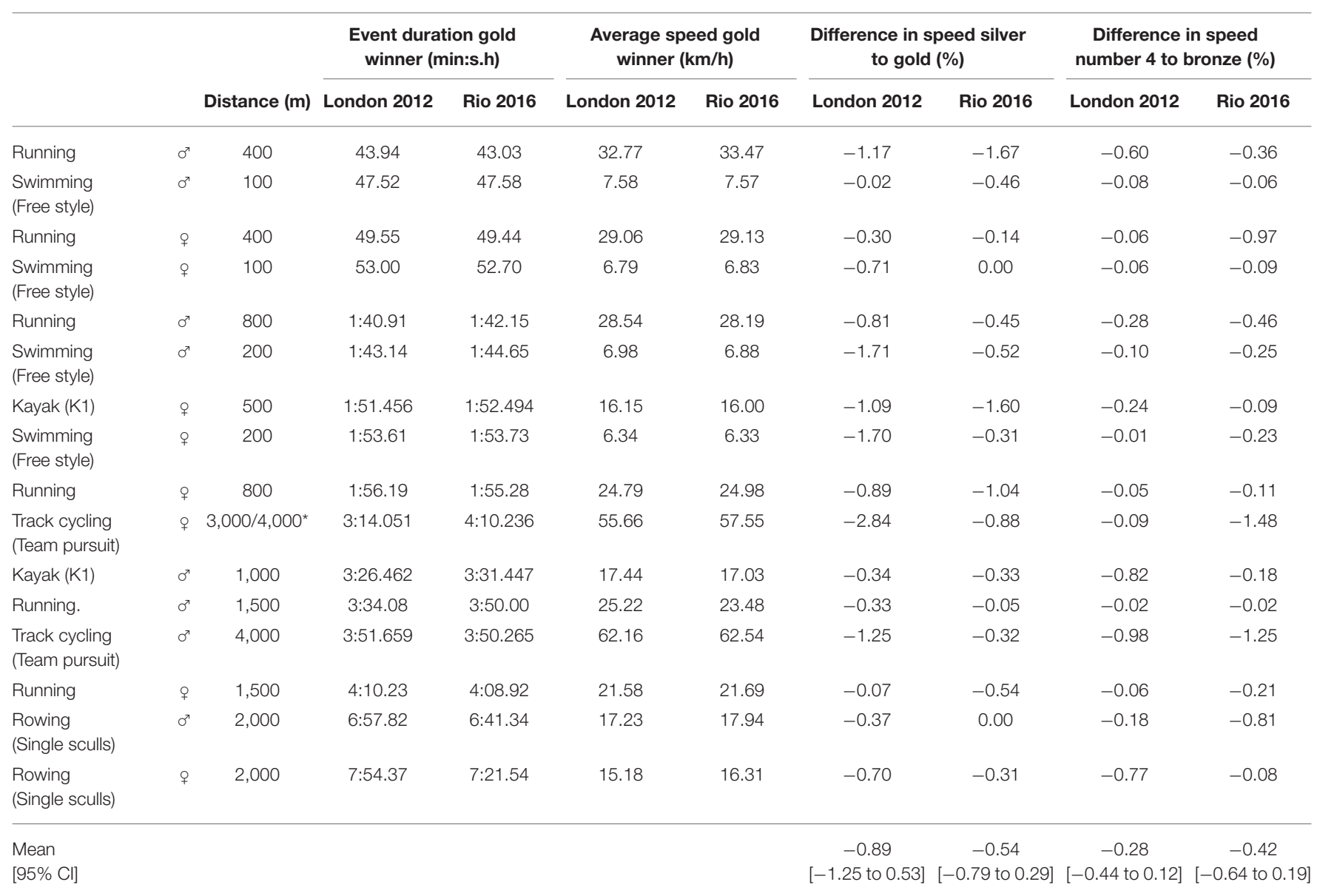

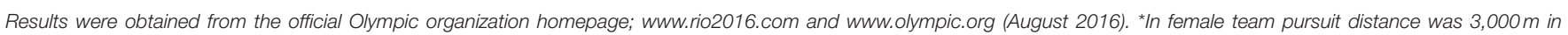
London and 4,000 m in Rio Olympics.

supplementation having a strict focus on closed-end performance evaluation in the time domain $45 \mathrm{~s}$ to $8 \mathrm{~min}$.

In turn, a secondary aim is to conduct a meta-analysis in which the isolated effects on performance from beta-alanine, bicarbonate, caffeine and nitrate supplementation is evaluated with the same methods allowing for a better comparison of the supplements ergogenic properties, since previous reviews mainly have been centered around a single supplement with various methods applied (e.g., mix of test protocols and large span in time domain).

\section{METHODS}

\section{Criteria for Study Selection}

Two researchers independently identified eligible peer-reviewed studies by a systematic search in the electronic database Medline (PubMed). The search strategy included the following medical subject heading (MeSH) terms: "humans," "betaalanine," "caffeine," "nitrate," and "bicarbonate." MeSH terms were combined with the following wild card strings "run*," "ski*," "swim*," "row*," "kayak*" as well as "cycling" and "intense exercise." A similar search strategy was applied in the database SPORTDiscus. Additional relevant studies were identified from cross-referencing. The search was terminated in April 2016.

Included studies utilized a single or double blind placebo controlled cross-over design, except for studies of beta-alanine where a single blinded parallel group design was allowed due to the long washout period of 6-15 weeks for beta-alanine (Baguet et al., 2009) and in this case data pre and post supplementation were included in the meta-analysis. Only studies applying performance test lasting from $45 \mathrm{~s}$ to $8 \mathrm{~min}$ with either a fixed duration or fixed distance in able bodied healthy human subjects were included. If several performance tests were conducted in a single study, only the results of the first performance test was included in case at least $20 \mathrm{~min}$ of recovery was applied between tests in order to avoid effects related to pacing and fatigue.

Studies were included if they adhered to the present consensus of optimal supplementation. For beta-alanine, the supplementation period should be 28 days or longer with ingestion of $\geq 3$ g per day (Derave et al., 2010). Bicarbonate doses of $\geq 0.2 \mathrm{~g} / \mathrm{kg}$ bodyweight ingested $>60 \mathrm{~min}$ before performance testing as well as multi-day bicarbonate intake of $\geq 0.3 \mathrm{~g} / \mathrm{kg}$ daily 
(McNaughton, 1992a; Siegler et al., 2010, 2012; Carr et al., 2011a) or pre-exercise infusion (Kindermann et al., 1977) was accepted. Caffeine supplementation of $\geq 2 \mathrm{mg} / \mathrm{kg}$ bodyweight supplied 30 min or longer before the performance test (Graham and Spriet, 1995; Pasman et al., 1995; Spriet, 2014) was included. Finally, acute nitrate ingestion of $\geq 4 \mathrm{mmol}, 120-300 \mathrm{~min}$ before the performance test (Vanhatalo et al., 2010b; Wylie et al., 2013) or chronic exposure was accepted.

For inclusion in the meta-analysis, performance results were required to be reported as an absolute group mean with a standard deviation or standard error of the mean, both before and after the intervention. In studies in which the standard error were reported, they were converted to standard deviations by multiplying the standard error by the square root of the sample size. Moreover, studies were required to report speed or an entity that was convertible to speed by standard methods (e.g., conversion to speed from time to cover a given distance in field tests or ergometer tests). In one study with rowing as exercise modality only mean power was reported for the 2,000$\mathrm{m}$ distance covered (Carr et al., 2012). This was converted to an average speed from the formula provided by the manufacture of the Concept II rowing ergometer used in that study:

$$
\text { Time pr. } 500 \mathrm{~m}=3 \sqrt{ } /(2.8 / \text { Power }(\text { watt }))
$$

In studies reporting mean power or total work from ergometer cycling (McNaughton, 1992a,b; McNaughton et al., 1997; Marx et al., 2002; Doherty et al., 2004; Vanhatalo et al., 2010a; Driller et al., 2012; Howe et al., 2013; Hoon et al., 2014a; Thomas et al., 2016) an average speed ( $\mathrm{v} ; \mathrm{m} / \mathrm{s})$ was determined numerically using the formula (Martin et al., 1998):

$$
\begin{aligned}
& \text { Power }(\text { watt })= \\
& \frac{\left(\left(0,5 \mathrm{CdA} \times \mathrm{Rho}^{*} \mathrm{v}^{2}\right)+\left(\text { total weight }{ }^{*} \mathrm{Crr}^{*} \mathrm{~g}\right)\right)^{*} \mathrm{v}}{(1-\text { drivetrain loss } \% / 100)}
\end{aligned}
$$

In the above calculation it is assumed that no windspeed or slope (gradient) is affecting the rider with the use of fixed values for $\mathrm{CdA}($ drag coefficient $\times$ frontal area $)=0.321$; Rho $($ air density $)=$ $1.226 \mathrm{~kg} / \mathrm{m}^{3}$, total weight (rider and bicycle; $\mathrm{kg}$ ) using a fixed bike weight of $8 \mathrm{~kg}$ and the average body weight listed in each study, Crr (Coefficient of rolling resistance) $=0.005$, g (gravitational force constant $)=9.8067 \mathrm{~m} / \mathrm{s}^{2}$, drivetrain loss $\%=3 \%$.

Accordingly, for all studies average speed and the corresponding standard deviation were calculated for each supplement and the placebo (bicarbonate, caffeine, nitrate) or pre supplementation (beta-alanine) condition.

Based on these criteria a total of $7,25,9$, and 5 studies of beta-alanine, bicarbonate, caffeine and nitrate, respectively, were included (Figure 1). Some of the included studies applied several performance tests.

\section{Study Quality}

Based on present guidelines from the Cochrane Institute (Higgins et al., 2011), study quality was assessed with the terms "high risk" or "low risk" of bias modified for exercise performance analyses (Table 2). The relative distribution of studies within each of the four supplements having high or low risk of bias are shown in Figure 2.

\section{Data Analysis}

Effect sizes (Cohens d) including a Hedges bias correction factor are displayed in forest plots based on standardized differences (SMD) calculated as

$$
\operatorname{SMD}=\frac{\left(\mathrm{X}_{\mathrm{s}}-\mathrm{X}_{\mathrm{c}}\right)}{\mathrm{S}_{\mathrm{p}}}
$$

where $\mathrm{X}_{\mathrm{s}}$ was average speed with supplementation, $\mathrm{X}_{\mathrm{c}}$ was average speed in the control situation (i.e., Placebo trials for bicarbonate, caffeine and nitrate and pre beta-alanine supplementation), and $\mathrm{S}_{\mathrm{p}}$ is the pooled standard deviation determined as

$$
\mathrm{Sp}=\frac{\operatorname{Squareroot}\left(\left(\mathrm{SDs}^{2} \times(\mathrm{n}-1) \pm \operatorname{SDc}^{2} \times(\mathrm{n}-1)\right)\right.}{(\mathrm{n}+\mathrm{n}-2)}
$$

where $\mathrm{SD}_{\mathrm{s}}$ is standard deviation with supplementation, $\mathrm{SD}_{\mathrm{c}}$ is standard deviation in the control situation and $\mathrm{n}$ is the number of subjects.

A multivariate meta-analysis was used to appropriate handle multiple and partly non-overlapping treatments between studies (van Houwelingen et al., 2002). Specifically, a mixed effects model was fitted to logarithm-transformed group means using maximum likelihood estimation; standard errors of logarithmtransformed means were used as weights. The five treatment groups were included as fixed effects in the model. The dependence between multiple means from the same studies was captured through the inclusion of study-specific random effects. Combined effects were estimated and the resulting differences between the four active treatments (supplementation) and control situation were reported (after back-transformation). A significance level of 0.05 was applied. Effect sizes was characterized as either trivial (0-0.2), small (0.2-0.6) or large (>0.6) (Hopkins et al., 2009). Analyses were carried out using the statistical environment R (R Core Team, 2016) with the extension package "metafor" (Viechtbauer, 2010).

\section{RESULTS}

\section{Beta-Alanine}

A total of 7 studies were identified including 72 subjects. $\mathrm{VO}_{2-}$ max as an objective measure of training status was reported in two of the studies (Howe et al., 2013; Bellinger and Minahan, 2016). The proportion of female subjects could not be precisely determined due to incomplete reporting of groups in one study (Painelli Vde et al., 2013) but amounted to $\sim 8 \%$. Two studies included several interventions with different performance tests (Painelli Vde et al., 2013; Bellinger and Minahan, 2016). Thus, 11 performance tests were included in the meta-analysis (Figure 3). The estimated combined effect size (with 95\% confidence interval) for $\beta$-alanine supplementation was 0.17 $[-0.12-0.46]$ which was not significantly different from the pre-supplementation trial $(P=0.24)$. 


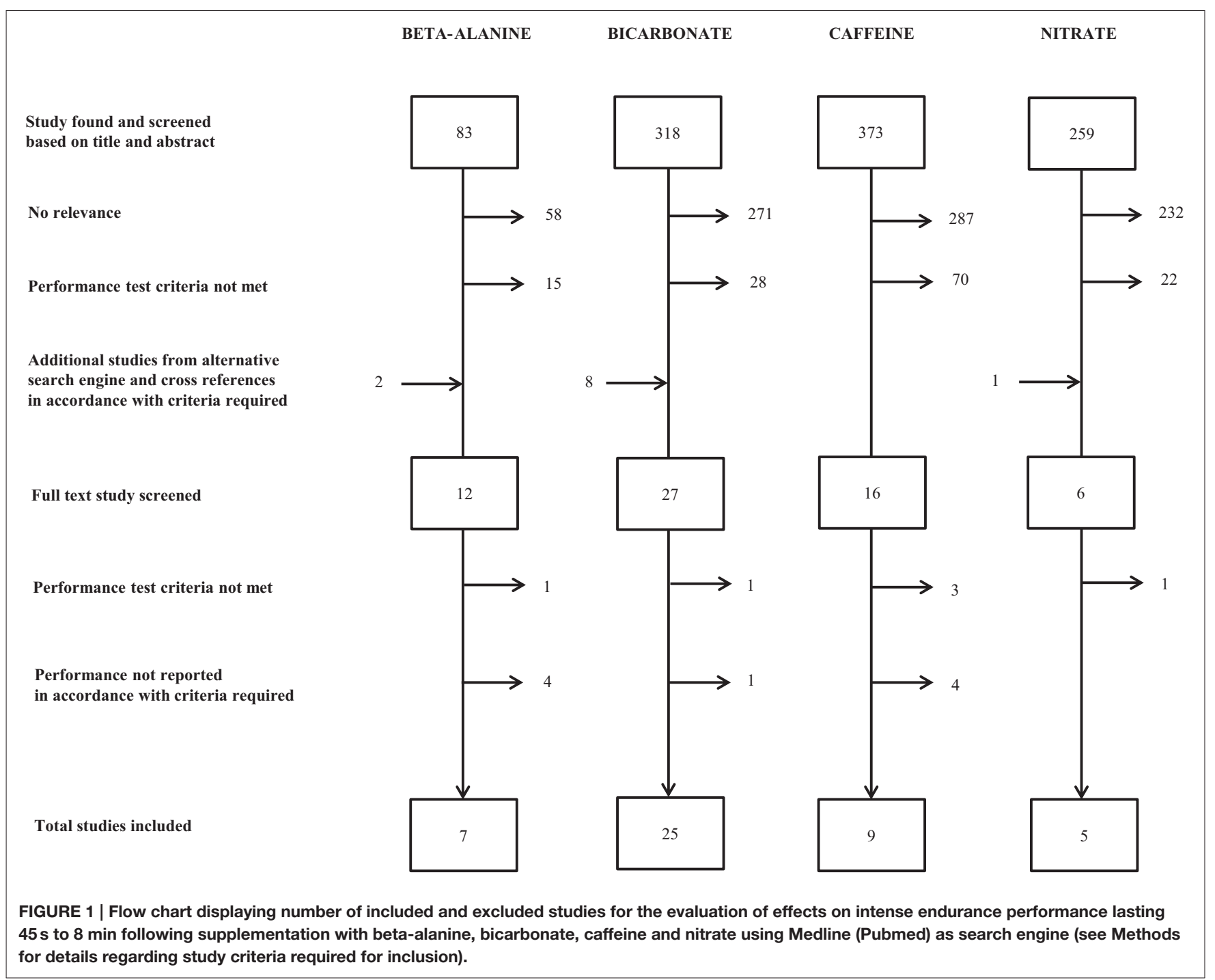

\section{Bicarbonate}

A total of 25 studies were identified including 235 subjects. $\mathrm{VO}_{2}$ max was reported in six of the studies (McNaughton, 1992a,b; McNaughton et al., 1997; Vanhatalo et al., 2010a; Driller et al., 2012; Thomas et al., 2016) and the female subject proportion was $\sim 9 \%$. Six studies included several interventions with different administration of bicarbonate (McNaughton, 1992a; Carr et al., 2012; Driller et al., 2012; Joyce et al., 2012) or evaluation of performance using several tests (McNaughton, 1992b; Painelli Vde et al., 2013). Thus, 33 performance tests were included in the meta-analysis (Figure 4). The estimated combined effect size of 0.40 [0.27-0.54] demonstrates a faster exercise speed after bicarbonate supplementation compared to placebo $(P<$ $0.001)$.

\section{Caffeine}

A total of 9 studies were identified including 97 subjects. $\mathrm{VO}_{2}$-max was reported in three of the studies (Wiles et al., 1992; Skinner et al., 2010; Santos Rde et al., 2013). Assuming only male subjects in protocol " 2 " by Wiles et al. (1992), the female subject proportion was $3 \%$. One study included several interventions with different administration of caffeine (Skinner et al., 2010) and one evaluated performance using several tests (Wiles et al., 1992). Thus, 12 performance tests were included in the meta-analysis (Figure 5). The estimated combined effect size of 0.41 [0.15-0.68] demonstrates a faster exercise speed after ingesting of caffeine compared to placebo $(P=0.002)$.

\section{Nitrate}

A total of 5 studies were identified including 66 subjects. $\mathrm{VO}_{2}$ max was reported in three of the studies and $8 \%$ of subjects were females. Three studies included several interventions with different administration of nitrate (Boorsma et al., 2014; Hoon et al., 2014a,b) and one study both manipulated administration and exercise testing (Peeling et al., 2015). Thus, 8 performance tests were included in the meta-analysis (Figure 6). The 
TABLE 2 | Definitions for high risk and low risk of bias in studies included in meta-analysis regarding the ergogenic potential from supplementation with beta-alanine, bicarbonate, caffeine and nitrate for increased performance in intense endurance sports.

\begin{tabular}{|c|c|c|}
\hline & High risk & Low risk \\
\hline $\begin{array}{l}\text { Commercial } \\
\text { affiliations }\end{array}$ & $\begin{array}{l}\text { Mention of } \\
\text { affiliations }\end{array}$ & No commercial affiliations \\
\hline Time of day & No info provided & Subjects performing at same time of day \\
\hline $\begin{array}{l}\text { Environmental } \\
\text { factors }\end{array}$ & No info provided & $\begin{array}{l}\text { Temperature and humidity reported (and } \\
\text { wind if outside) }\end{array}$ \\
\hline Warm-up & $\begin{array}{l}\text { No info provided } \\
\text { or free warm-up }\end{array}$ & $\begin{array}{l}\text { Fixed based on a relative intensity or } \\
\text { maintained intra-subject warm-up but } \\
\text { differences between subjects }\end{array}$ \\
\hline Timing of dose & No info provided & Info provided \\
\hline $\begin{array}{l}\text { Test } \\
\text { familiarization }\end{array}$ & No info provided & Mention of familiarization \\
\hline $\begin{array}{l}\text { Diet pre-test } \\
\text { day }\end{array}$ & No info provided & $\begin{array}{l}\text { Controlled diet including subjects } \\
\text { instructed to eat similar meal }\end{array}$ \\
\hline $\begin{array}{l}\text { Activity pre-test } \\
\text { day }\end{array}$ & No info provided & Controlled training \\
\hline Drop out & No info provided & Number of drop outs reported \\
\hline Blinding & Single Blinded & Double blinded \\
\hline Randomization & $\begin{array}{l}\text { No mention of } \\
\text { randomization }\end{array}$ & Mention of randomization \\
\hline
\end{tabular}

estimated combined effect size of $0.19[-0.03-0.40]$ tended to be different from placebo $(P=0.09)$.

\section{Correlations}

For all data pooled a modest association was observed between performance test time and percentage improvement $\left(r^{2}=\right.$ $0.17, P<0.001)$ implying slightly greater performance gains with reductions in performance test time (Figure 7). A similar observation was found for bicarbonate $\left(r^{2}=0.19, P<0.05\right)$ and caffeine $\left(r^{2}=0.45, P<0.05\right)$, while no association were seen for beta-alanine $\left(r^{2}=0.07\right)$ and nitrate $\left(r^{2}=0.0001\right)$.

\section{DISCUSSION}

The primary finding in the present meta-analysis is that a small yet significant effect on performance was observed by prior supplementation with caffeine (Effect size, ES $=0.41$ ) or bicarbonate $(\mathrm{ES}=0.40$ ) resulting in a higher average speed during closed-end intense endurance exercise tests lasting $45 \mathrm{~s}$ to $8 \mathrm{~min}$. No significant performance effect was detectable for supplementation with beta-alanine or nitrate, with both supplements having a trivial effect $(\mathrm{ES}=0.17-0.19)$ (Figure 8).

\section{Beta-Alanine}

Based on the 11 performance tests from the 7 included studies with a total of 72 subjects the present analysis demonstrates that beta-alanine supplementation cannot be concluded to be ergogenic in competitive intense endurance sports (Figures 3, 8). This is in contrast to the position stand of the international society of sports nutrition where it is stated that beta-alanine supplementation generally enhances intense exercise lasting more than $60 \mathrm{~s}$ (Trexler et al., 2015). In this context, it is important to note that this was primarily found for open-end exercise tests and not the competition relevant time trial test. In line with the conclusion from the present analysis, Hobson et al. (2012) also reported no significant performance effect of betaalanine supplementation despite improved time to exhaustion based on mixed exercise protocols and Saunders et al. (2017) found that the effect of beta-alanine was $\sim 5$ times as high in open-end tests as in performance relevant closed-end tests.

Due to the long supplementation period $(\sim 1$ month) a concern with all beta-alanine studies is to discriminate between effects from the supplementation per se and time effects (e.g., higher or lower training status during the supplementation period). The use of a placebo group or a cross-over design is required to discriminate between effects of supplementation per see or time-effects. Accordingly, in one of the included studies, Derave et al. (2007) reported similar improvement in the placebo and beta-alanine group implying that the changes in performance in the former group could be attributed to other factors than the supplement.

It is unclear how beta-alanine supplementation should improve human exercise performance but the most often suggested possibilities are a higher muscle carnosine content which may increase intramuscular buffer capacity (Parkhouse et al., 1985), increase calcium sensitivity and/or increase calcium release (Dutka et al., 2012) or improve anti-oxidant capacity (Kohen et al., 1988; Pavlov et al., 1993). The paresthethic effect of beta alanine occurring in $0 \%$ (Derave et al., 2007; Hobson et al., 2013), 15\% (Bellinger and Minahan, 2016), $\sim 25 \%$ (Howe et al., 2013), or $\sim 50 \%$ of participants (Painelli Vde et al., 2013) in the included studies can be speculated to cause a placebo-effect. Still, performance gains around $1 \%$ as observed in many of the individual studies (Figures 3, 7) is considered relevant to explore for high performance intense endurance athletes (Table 1) irrespective of the mechanism(s). At present larger studies of elite athletes are required and/or studies of individual responses that can be reproduced which in turn may be affected by factors such as gender, diet and muscle fiber type distribution (Derave et al., 2010). Taken together, the present meta-analysis underlines that no clear ergogenic effect of betaalanine supplementation can be expected in competitions lasting from $45 \mathrm{~s}$ to $8 \mathrm{~min}$.

\section{Bicarbonate}

Bicarbonate supplementation significantly improved performance. The analysis was based on a total of 33 performance tests from 25 studies with a total of 235 subjects (Figures 4, 8). The present finding is in agreement with the recommendation of using bicarbonate as an ergogenic compound when competing in events lasting 1-10 min (Carr et al., 2011a). Contrary to the comprehensive analysis of Carr et al. (2011a) we only included performance relevant tests by excluding open-end test protocols, which is considered of great practical importance for athletes since time to exhaustion testing may introduce larger variability because of motivational and mental aspects (Jeukendrup et al., 1996; Laursen et al., 2007). 


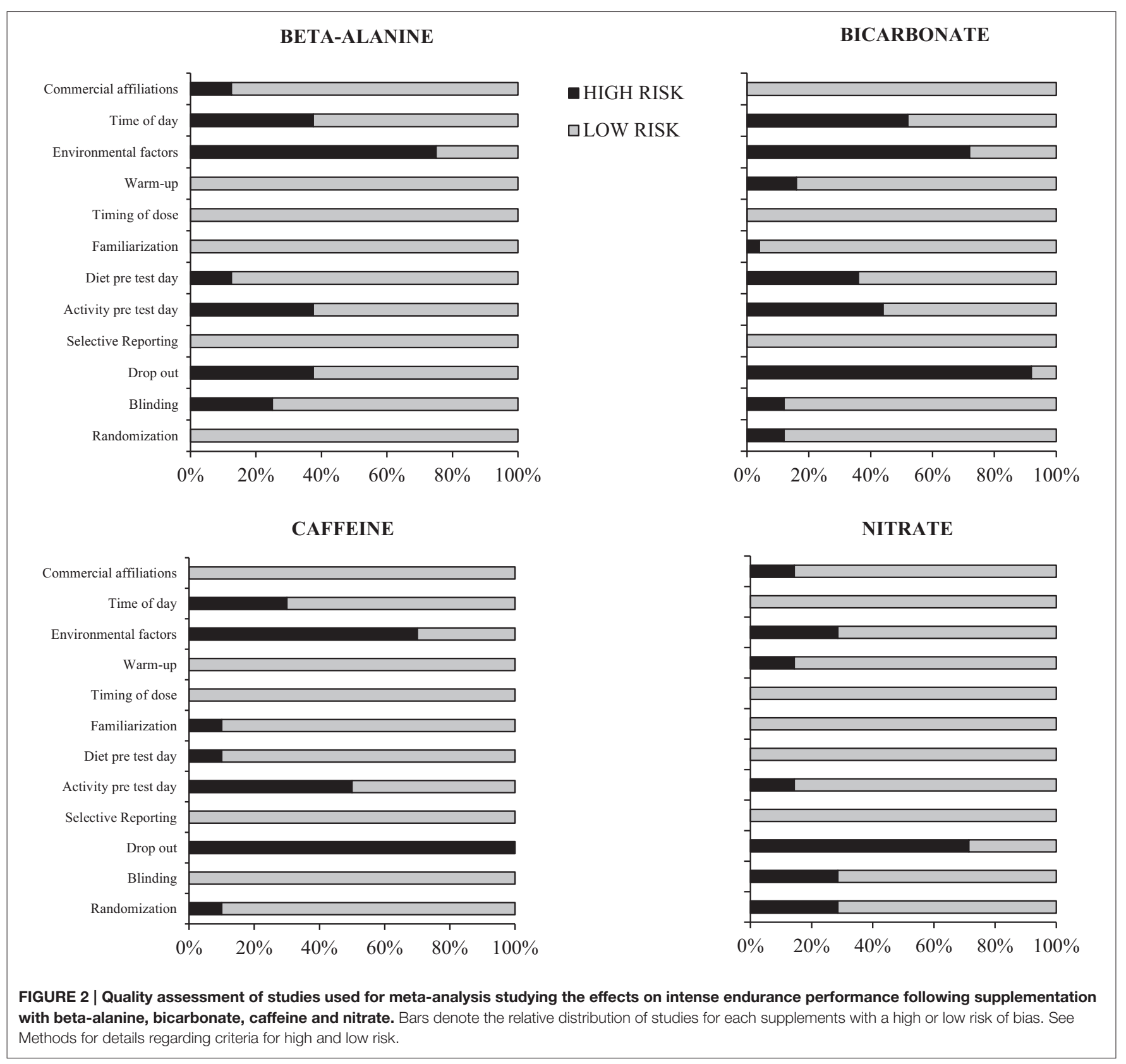

It is important to note that exclusion of just one performance test (of a total of 33 tests with 235 subjects) - originating from the study of 5 rowers by McNaughton and Cedaro (1991) having a substantial high effect size (Figure 4)-causes a marked change of both the $p$-value (from below 0.001 to 0.06 ) and the combined effect size (from 0.40 to 0.19 ). Accordingly, a balanced interpretation of the data included in the analysis is warranted. Nevertheless, the potential for bicarbonate to improve intense endurance performance seems apparent albeit small, both with (small combined effect size being highly significant different from placebo) or without (combined effect size trivial close to small tending to be different from placebo) inclusion of that particular study.
As with beta-alanine supplementation, bicarbonate's mechanism of action is not fully established but possibly includes increased blood and/or muscle buffer capacity leading to improved protection of muscular contractility via reduced intra- and extracellular $\mathrm{H}^{+}$accumulation (Raymer et al., 2004), potentially affecting calcium sensitivity (Nelson and Fitts, 2014), improved potassium handling (Street et al., 2005), diminished arterial desaturation (Nielsen et al., 2002) or reduced type III/IV afferent firing (Amann et al., 2015). In turn, reductions in blood $\mathrm{pH}$ and bicarbonate prior to exercise is known to impair subsequent rowing performance following ammonium chloride ingestion (Brien and McKenzie, 1989) and one legged knee extensor exercise capacity following prior intense arm 


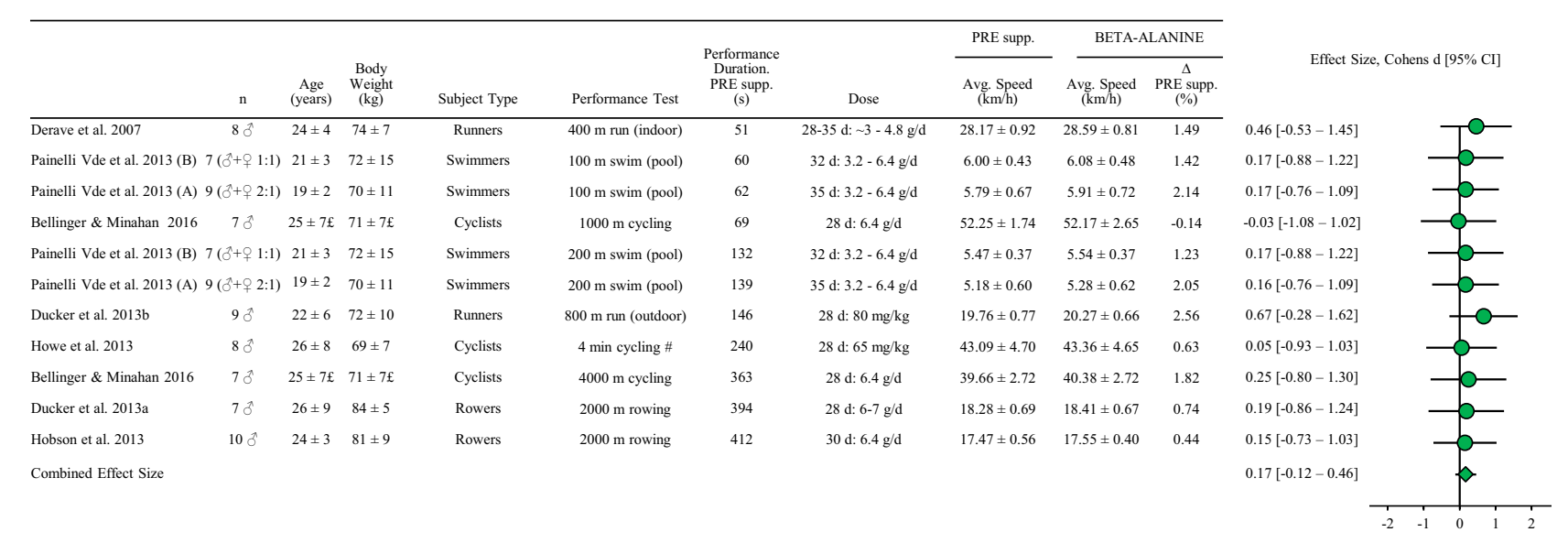

FIGURE 3 | Standardized mean difference (effect size) with $95 \%$ confidence intervals as reported in studies of beta-alanine supplementations effect on performance (average speed) relative to pre supplementation in athletic endurance events lasting $\mathbf{4 5} \mathrm{s}$ to $\mathbf{8}$ min. The combined effect size has been calculated as described in methods section. All other data is reported as mean \pm SD. All performance tests were executed indoors on ergometers or treadmills unless stated differently. Regarding Dose: Dose in each study is displayed as days (d) of consumption with the daily dose as gram pr day (g/d). \# Speed estimated from mean power reported. ${ }^{\complement}$ Group mean reported $(n=14)$; no info on placebo $(n=7)$ and beta-alanine $(n=7)$ group separately.

exercise (Bangsbo et al., 1996; Nordsborg et al., 2003). Thus, the typical increase in blood $\mathrm{pH}$ of $\sim 0.1$ and bicarbonate concentration of $\sim 5 \mathrm{mM}$ with supplementation (Carr et al., 2011a) may be sufficient to postpone fatigue mechanisms during intense endurance exercise. Based on simple regression analysis, bicarbonate may be more ergogenic in shorter (e.g., $1 \mathrm{~min}$ ) than longer (e.g., $6 \mathrm{~min}$ ) performance tests (Figure 7). Nevertheless, the weak association illustrates that more studies are needed, for example including several performance tests of varying duration (e.g., 1, 4, and $8 \mathrm{~min}$ ) executed by the same subjects. It should be noted that marked individual differences may exist. For example, bicarbonate supplementation caused gastro intestinal problems in 4 out of 21 subjects prior to a time to exhaustion test and exclusion of these four participants resulted in a significant increased exercise time during intense cycling exercise (Saunders et al., 2014). Additionally, there appear to be marked individual differences in bicarbonate uptake kinetics (Jones et al., 2016) and high level athletes may benefit from an individualized protocol (Miller et al., 2016) but this also needs to be addressed in future studies.

\section{Caffeine}

Average speed in intense endurance performance tests lasting $45 \mathrm{~s}$ to $8 \mathrm{~min}$ is increased by caffeine supplementation. The finding is based on 12 different performance tests from 9 studies with a total of 97 subjects (Figures 5, 8). In half of the studies the improvement in speed exceeded $1 \%$ relative to placebo. This observation is in line with a previous narrative review highlighting caffeine as an ergogenic compound for speed endurance events lasting 1-3 min (Davis and Green, 2009) as well as reviews that focus on longer duration exercise lasting several hours (Doherty and Smith, 2004; Ganio et al., 2009). Thus, the present meta-analysis adds to the existing knowledge by establishing that caffeine is also ergogenic in the time domain from $45 \mathrm{~s}$ up to $8 \mathrm{~min}$. The present result is in apparent contradiction with the notion that caffeine is less ergogenic in short relative to long-term exercise tests (Doherty and Smith, 2004). However, the previous meta-analysis included both open and closed end exercise testing and different time intervals. Therefore, the discrepancy may be related to the strict selection criteria in the present study, yet both studies outline the ergogenic potential from caffeine in multiple types of exercise tasks. The present meta-analysis does not allow for an evaluation of the interaction between exercise time and caffeine's effect. However, a simple regression analysis based on the non-weighed average effect of the included studies suggests that a larger ergogenic effect may be expected during shorter as compared to longer intense exercise within the time domain of $45 \mathrm{~s}$ to $8 \mathrm{~min}$ (Figure 7). However, more systematic studies on the possible interaction between exercise duration and magnitude of effect are required before conclusions can be drawn.

Several possibilities exist regarding caffeine's ergogenic effect. These include antagonizing binding of adenosine to its brain receptors which may cause reduced perception of effort and increased arousal and/or peripheral inhibition of muscle pain (Davis and Green, 2009). In support of this notion, participants following caffeine intake report lower perceived exertion during exercise with the same absolute exercise intensity (Doherty et al., 2004; Miller et al., 2014) and in 5 min intervals a similar level of perceived exertion despite a higher mean power with caffeine (Lane et al., 2013). In line herewith, the same degree of exertion has been reported between placebo and caffeine trials during intense endurance performance tests despite improved performance in the latter condition (Santos Rde et al., 2013; Christensen et al., 2014). However, the performance enhancing effect of caffeine may also be related to improved muscle contractility caused by reduced $\mathrm{K}^{+}$accumulation during intense exercise (Mohr et al., 2011) or even by the augmented adrenergic response to caffeine supplementation 


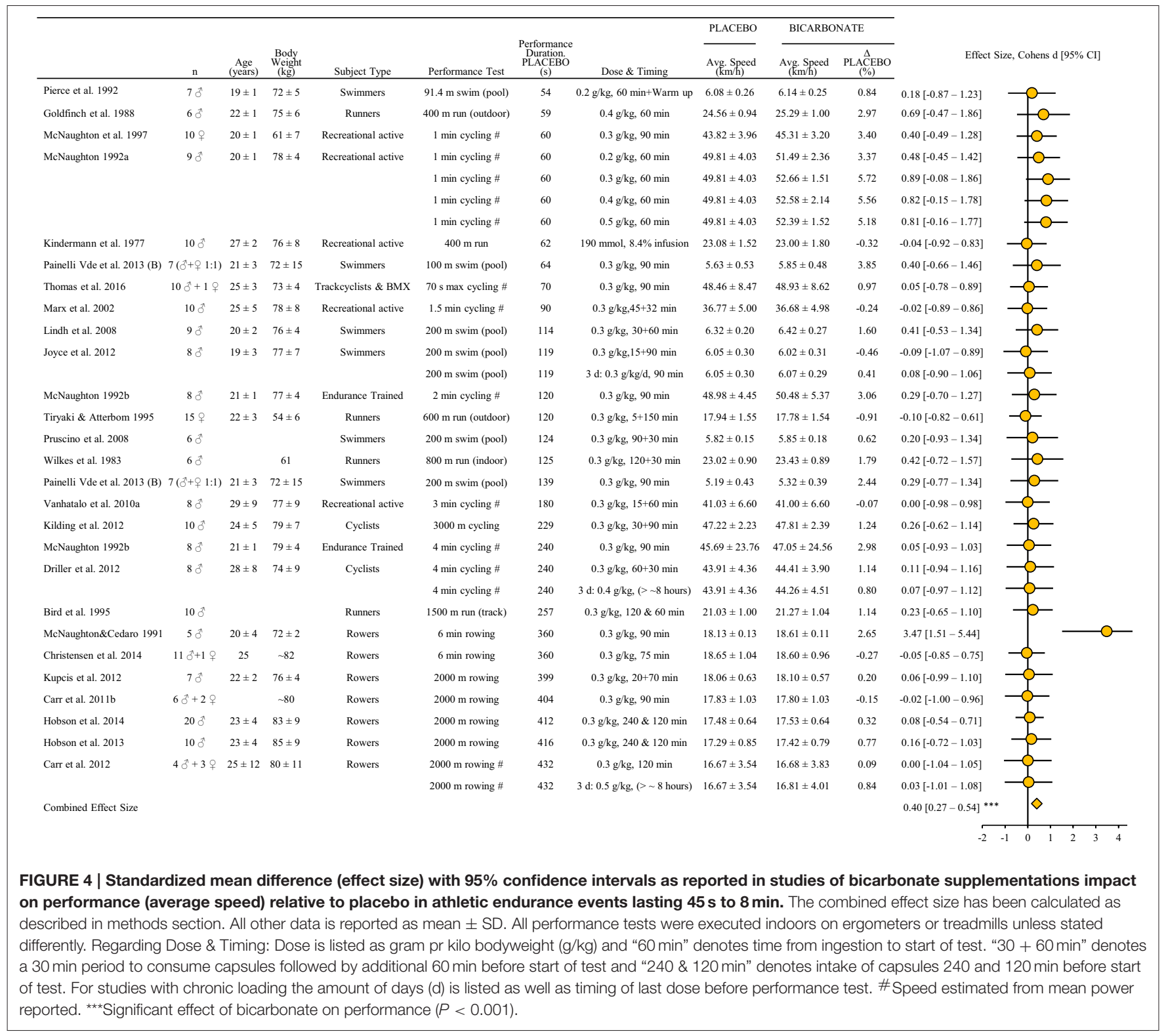

associated with a larger glycolytic energy turnover during intense endurance exercise (Jackman et al., 1996) although this has been challenged as the main mechanism for the ergogenic effect (Davis and Green, 2009). The exact mechanism of action in specific exercise situations may differ and remains to be elucidated. Caffeine doses in the included studies ranged from 2 to $6 \mathrm{mg} / \mathrm{kg}$ body weight, which is in accordance with previous guidelines (Spriet, 2014). Taken together, caffeine appears to improve exercise performance lasting $45 \mathrm{~s}$ to $8 \mathrm{~min}$.

\section{Nitrate}

Nitrate supplementation did not significantly improve average speed in the 8 performance tests extracted from the 5 included studies with a total of 66 subjects (Figures 6, 8). Accordingly, previous meta-analyses have reported unclear effects in performance tests with a large range in exercise time (Hoon et al., 2013) or with a mix of protocols (Braakhuis and Hopkins, 2015). However, a tendency $(P=0.09)$ for an effect was identified, underpinning the importance of future well-controlled studies designed to identify small effects (i.e., $<1 \%$ on average speed) and/or repeatable individual responses. It is noteworthy that nitrate supplementation does not appear to exert any physiologic or endurance performance enhancing effects on group level in highly trained endurance athletes with an average $\mathrm{VO}_{2}$-max exceeding $70 \mathrm{ml} / \mathrm{min} / \mathrm{kg}$ (Peacock et al., 2012; Christensen et al., 2013; Boorsma et al., 2014; Porcelli et al., 2015). Moreover, in a cross sectional study encompassing $\mathrm{VO}_{2}$-max values between 28 and $81 \mathrm{ml} / \mathrm{min} / \mathrm{kg}$, $\mathrm{VO}_{2}$-max explained more than $75 \%$ of the magnitude of improvement in performance during a $3 \mathrm{~km}$ run (Porcelli et al., 2015). In line herewith, the largest percentage performance 


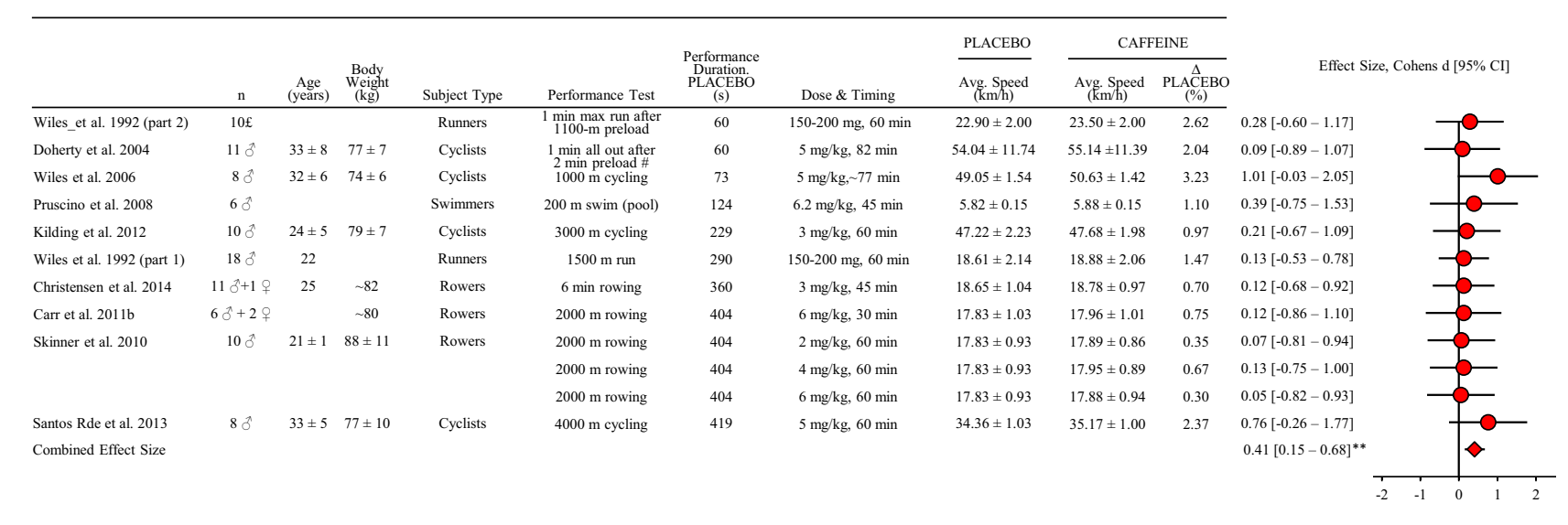

FIGURE 5 | Standardized mean difference (effect size) with $95 \%$ confidence intervals as reported in studies of caffeine supplementations impact on performance (average speed) relative to placebo in athletic endurance events lasting $\mathbf{4 5} \mathrm{s}$ to $\mathbf{8} \mathrm{min}$. The combined effect size has been calculated as described in methods section. All other data is reported as mean $\pm \mathrm{SD}$. All performance tests were executed indoors on ergometers or treadmills unless stated differently. Regarding Dose \& Timing: Dose is listed as milligram pr. kilo bodyweight (mg/kg) and "60 min" denotes time for consumption before the performance test. \# Speed estimated from mean power reported. ${ }^{£}$ Four of the 10 subjects were also subjects in part 1 of the study. ${ }^{\star \star}$ Significant effect of caffeine on performance $(P<$ 0.01).

effect with nitrate supplementation in the present analysis is observed in the recreational active cyclists undertaking a 4,000-m time trial (Lansley et al., 2011). Interestingly, highly trained kayakers competing at international level experienced improved performance after nitrate supplementation (Peeling et al., 2015) implying that training status probably is not the sole determinant of nitrates ergogenic potential. Important factors may include high or low dietary nitrate intake from vegetable consumption (Jonvik et al., 2016), initial plasma levels of nitrite (Christensen et al., 2017) and muscle fiber composition in the engaged muscles since rat studies demonstrate a larger effect on blood perfusion after nitrate supplementation in muscles with a large proportion of fast twitch fibers (Ferguson et al., 2013).

Nitrate $\left(\mathrm{NO}_{3}^{-}\right)$supplementation increases bioavailability of nitrite $\left(\mathrm{NO}_{2}^{-}\right)$and has been found to lower energy expenditure during exercise and lower resting blood pressure (Larsen et al., 2007), likely due to higher levels of nitric oxide (NO) affecting muscle mitochondria and the circulation (Jones, 2014). The trained human is characterized by a high endogenous capacity for NO production (McConell et al., 2007; Nyberg et al., 2012) which likely is a large contributing factor as to why nitrate supplementation exerts modest physiologic effects in highly trained individuals (Peacock et al., 2012; Christensen et al., 2013; Boorsma et al., 2014; Porcelli et al., 2015). Still reports exist of "responders" in groups of trained (Wilkerson et al., 2012) and highly trained endurance athletes (Christensen et al., 2013; Boorsma et al., 2014) in endurance events besides the report on world class kayakers by Peeling et al. (2015). Thus, future well-designed investigations of possible individual effects of nitrate supplementation are required. At present nitrate supplementation does not appear to have a clear ergogenic effect on intense endurance performance, and the possibility to achieve an ergogenic effect seems greater for moderately trained subjects compared with highly trained endurance athletes.

\section{Methodologic Considerations}

It is of importance to consider that a publication bias may exist in the field of ergogenic supplements as it may be easier to publish studies demonstrating performance enhancing effects as compared to studies with no effect that are often under powered to exclude that an effect may exist. We terminated our study search in April 2016 but the field of ergogenic supplements continues to evolve. Recently, studies has been published showing no effect on intense endurance performance from both bicarbonate (Callahan et al., 2016) and nitrate (Callahan et al., 2016) supplementation whereas caffeine has resulted in both unchanged (Cordingley et al., 2016) and improved performance (Boyett et al., 2016). A number of the included studies in the current meta-analysis also reported negative findings, so to what extent an actual publication bias toward positive results exits remains unknown. Nevertheless, reporting of negative results are encouraged in order to provide a balanced and hence accurate foundation for future metaanalyses.

Importantly, the current quality assessment of the included studies displayed a low risk of bias, apart from reporting dropouts and environmental factors and to a lesser extent time of day for testing and activity the day prior testing (Figure 2) which future studies are encouraged to report.

Other important considerations are the potential impact of age, training status and gender for the observed effects of various supplements on performance. The range in average age among all of the included studies investigated was 19-33 years which provides high ecologic validity for athletes competing at the highest international level (e.g., Olympics). Still, further studies are required to clarify if other effects can be observed in athletes 


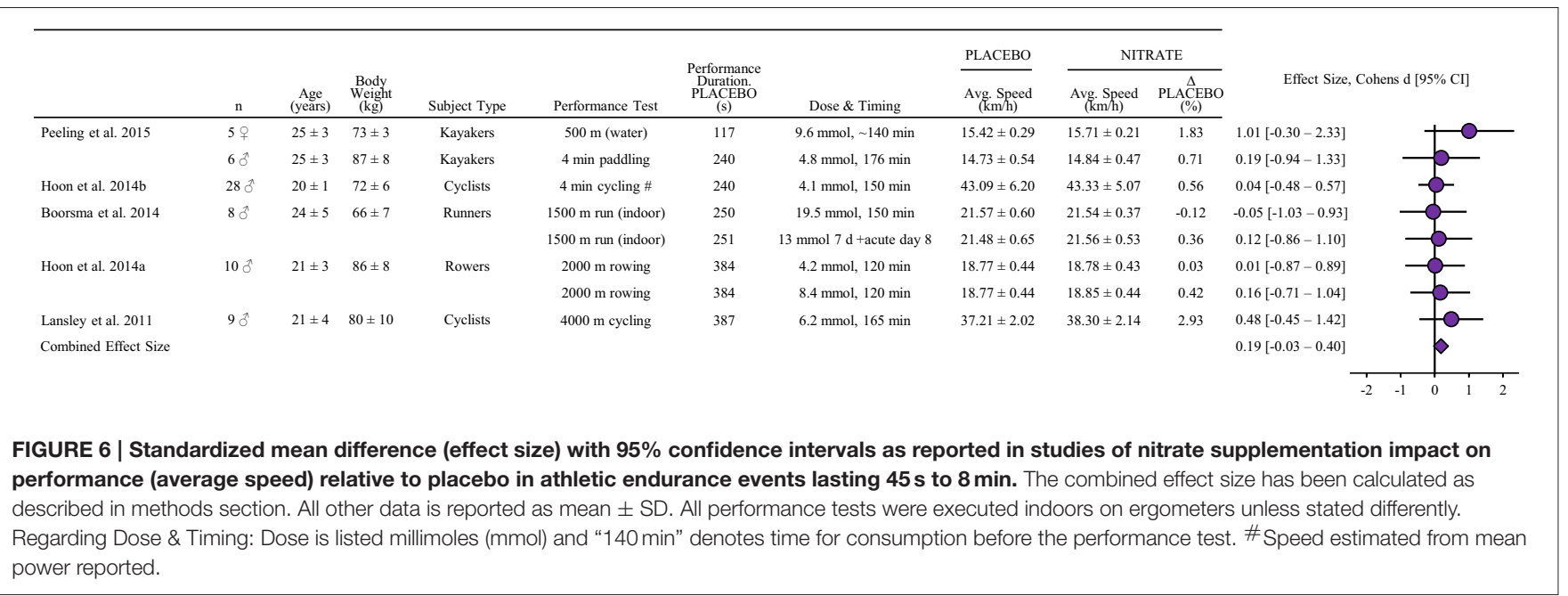

aged for example 30-40 years or even older. Regarding training status, only $\sim 30 \%$ of the studies reported maximal oxygen uptake as an objective index of cardio-respiratory capacity and little information was provided about training history. Thus, albeit relevant as highlighted for the nitrate studies, the few studies reporting objective measures of training status preludes an analysis of the general impact of training status. Several studies report their participants to be "trained," "well-trained," or "elite" but the used criteria is unclear. An additional challenge in comparing training status, for example based on reported power outputs, is that different methods of obtaining power is known to yield different results. In cycling for instance, differences of $10 \mathrm{~W}$ or more at $\sim 400 \mathrm{~W}$ is not uncommon (Duc et al., 2007; Kirkland et al., 2008). Nevertheless, an impression of performance level can be obtained by comparing the individual studies performance speed (Figures 3-6) with the velocities of top competitors at the Olympics provided in Table 1. Finally, it is evident that most studies in the present meta-analysis have been conducted with male subjects (Figures 3-6) as the proportion of female subjects did not exceed $10 \%$ for any of the four supplements. Thus, it is of relevance to investigate female subjects to a greater extent in future studies. Included studies dominated by females observe both large (McNaughton et al., 1997) and minor (Tiryaki and Atterbom, 1995) effects following bicarbonate intake while large effects also are seen after nitrate supplementation (Peeling et al., 2015).

\section{Perspectives}

In the present meta-analysis, a trivial effect on intense endurance performance was found for beta-alanine $(\mathrm{ES}=0.17)$ and nitrate $(\mathrm{ES}=0.19)$ while small and significant ergogenic effects was found for caffeine $(\mathrm{ES}=0.41$ ) and bicarbonate $(\mathrm{ES}=0.40)$. This does highlight that only marginal gains can be expected from supplementation with the four substances (Figure 8). In turn, it is important to note that youth athletes (Eisenmann et al., 2001; Tønnessen et al., 2015) and mature sub-elite athletes (e.g., Esfarjani and Laursen, 2007; Young et al., 2014) in regards

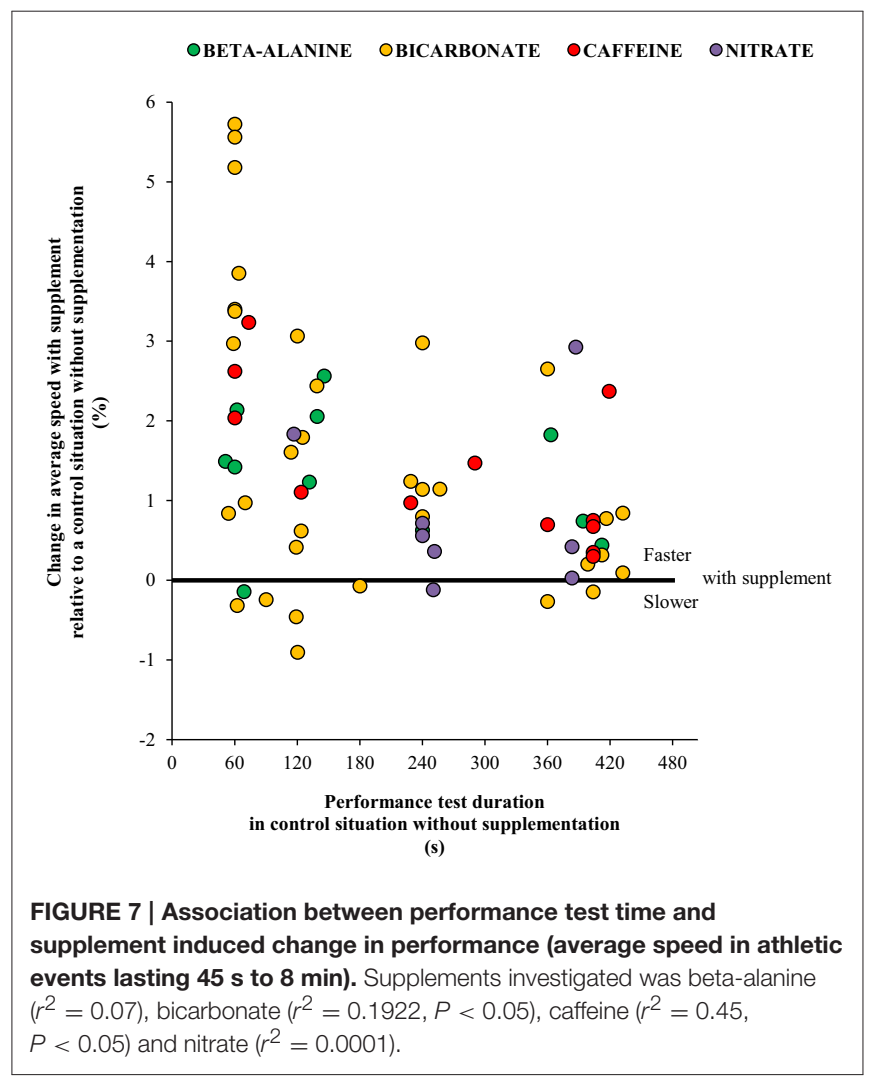

to endurance performance can benefit more from physiologic training and maturation rather than supplementation.

Still, supplementation is considered highly relevant for high performance athletes for whom very small margins separate medal rankings during competition (Table 1). Based on the results from the meta-analysis, caffeine and bicarbonate are considered the primary supplements for intense endurance athletes but even a trivial effect from beta-alanine and nitrate may provide an advantage during competition. Accordingly, athletes are encouraged to an individual approach in order to obtain 


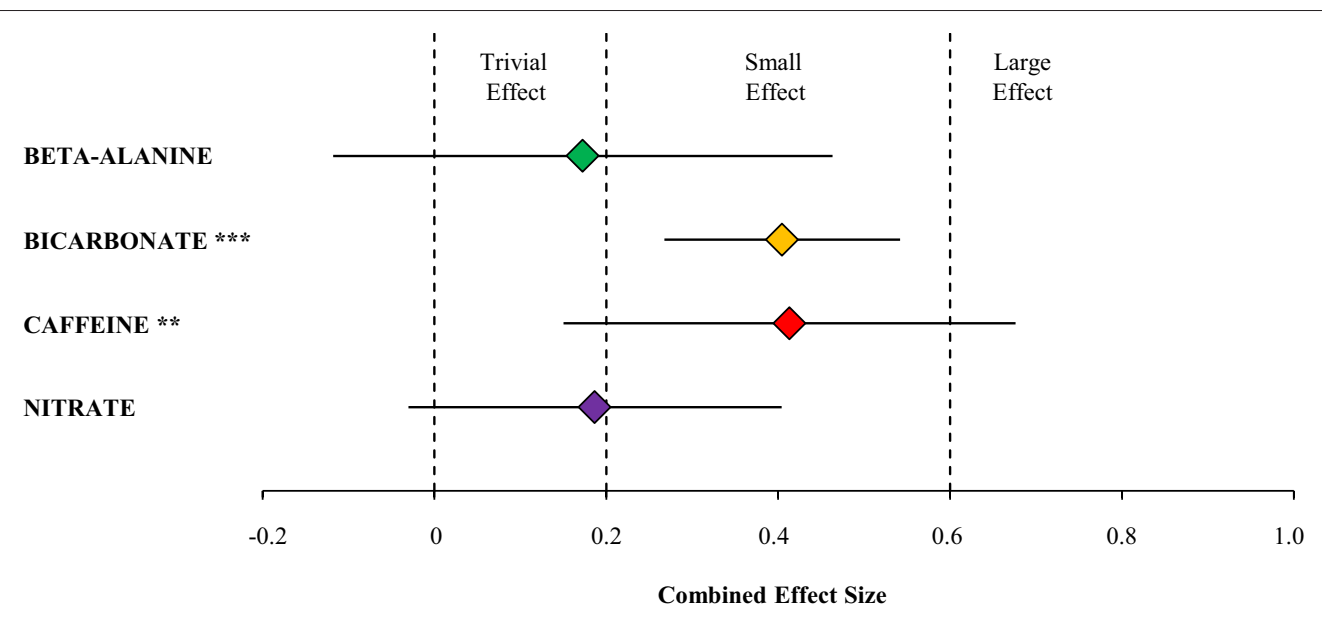

FIGURE 8 | Combined effect size with $95 \%$ confidence interval displaying the impact on performance (average speed) in athletic endurance events lasting $45 \mathrm{~s}$ to $8 \mathrm{~min}$ from supplementation with either beta-alanine (7 studies) relative to pre supplementation, bicarbonate (25 studies), caffeine ( 9 studies) or nitrate (5 studies) relative to placebo. Hatched lines display boundaries for effect sizes being trivial $(<0.2)$, small $(0.2-0.6)$ or large (>0.6). ${ }^{\star \star \star}$ Significant effect of bicarbonate on performance $(P<0.001)$. ${ }^{*}$ Significant effect of caffeine on performance $(P<0.01)$.

knowledge regarding what supplement(s) has the greatest effect on performance.

Relatively few of the included studies in the present analysis combined use of several supplements with combinations present for caffeine and bicarbonate (Pruscino et al., 2008; Carr et al., 2011b; Kilding et al., 2012; Christensen et al., 2014) and betaalanine and bicarbonate (Hobson et al., 2013; Painelli Vde et al., 2013). This could be the scope for future studies and help highlight if physiologic interactions between supplements exists and also holds practical importance for high level athletes and staff. Results are mixed for combined administration of caffeine and bicarbonate. Accordingly, using a traditional statistical approach (significance $P<0.05$ ) both supplements improved $4000 \mathrm{~m}$ cycling performance relatively to placebo but the combination of both did not lead to a greater performance than with single supplementation (Kilding et al., 2012). In rowing caffeine both with and without bicarbonate improved performance (Christensen et al., 2014), unlike observations using magnitude-based inferences statistics where bicarbonate abolished the improvement in performance with caffeine alone (Carr et al., 2011b). Adding bicarbonate to beta-alanine supplementation has been reported to improve 2,000 $\mathrm{m}$ rowing (Hobson et al., 2013) as well as 100 and $200 \mathrm{~m}$ swimming performance (Painelli Vde et al., 2013) with magnitude-based inference statistics, but not with traditional statistics (Painelli $\mathrm{Vde}$ et al., 2013). In a recent meta-analysis including a mix of exercise protocols beta-alanine together with bicarbonate induced a significant effect relative to use of beta-alanine alone (Saunders et al., 2017). Clearly more studies are needed to establish if positive or negative interactions between supplements are present.

Legal supplements other than the four analyzed in the present meta-analysis exist that may also impact on intense endurance performance. Creatine has been investigated in a few studies with reports of both unchanged (Burke et al., 1996; Mujika et al.,
1996; Syrotuik et al., 2001; De Andrade Nemezio et al., 2015) and improved performance (Rossiter et al., 1996; McNaughton et al., 1998). Importantly the majority of these studies reported mean power from ergometers (Rossiter et al., 1996; McNaughton et al., 1998; Syrotuik et al., 2001; De Andrade Nemezio et al., 2015) but for athletes in which body mass often is a concern it is important to account for any increase in weight which is common with creatine supplementation (Mujika et al., 1996; McNaughton et al., 1998; De Andrade Nemezio et al., 2015). Accordingly, an increased body weight will increase resistive forces on an athlete during forward propulsion leading to a higher energy expenditure for a given speed especially during running (LeCheminant et al., 2009) and in the water (Mujika et al., 1996).

Another supplement is the antioxidant n-acetyl cysteine (NAC) which following oral intake did not alter a 2-5 min timetrial performance in one study (Slattery et al., 2014) but enhanced exercise capacity in time to exhaustion tests lasting $\sim 8 \mathrm{~min}$ in another study (Corn and Barstow, 2011) but more studies are needed to establish if oral intake of NAC may be performance enhancing.

In light of the central actions that caffeine exerts during exercise lowering perception of effort (Doherty et al., 2004; Lane et al., 2013; Santos Rde et al., 2013; Christensen et al., 2014; Miller et al., 2014) the use of analgesic substances not banned at present may also exert an ergogenic effect. This is partly supported by improved time-trial performance (lasting 26 min) and similar perception of effort as with placebo in trained cyclists after intake of $1,500 \mathrm{mg}$ acetaminophen (Mauger et al., 2010) which is a mild over-the-counter analgesic in most countries. In cycling, the presence of the morphine like drug Tramadol in $\sim 5 \%$ of all samples analyzed in 2015 by the World AntiDoping Agency (WADA) also seems to indicate that performance enhancement may be present with administration of analgesic substances (WADA, 2015). This area is poorly explored and 
confer ethical considerations even though the net response of a reduced perception of effort appears similar to caffeine, albeit by different methods and with different potential side effects (Doherty et al., 2004; Lane et al., 2013; Miller et al., 2014).

For future studies we encourage use of individual data and ideally repeated use of a given supplement to better discriminate between day-to-day variation and true performance effects for the individual subject/athlete. This may also shed light on potential mechanisms for a supplement (not) to work if combined with other measures such as dietary habits, gender, muscle fiber distribution, mitochondrial capacity, buffer capacity, lactate production and adrenergic response during exercise.

\section{CONCLUSION}

Using a meta-analytic approach with a strict focus on "closedend" (e.g., time-trials or fixed duration) intense endurance performance tests lasting from $45 \mathrm{~s}$ to $8 \mathrm{~min}$, prior intake of caffeine or bicarbonate demonstrated a small positive effect on average speed being significantly different from placebo. Nitrate

\section{REFERENCES}

Amann, M., Sidhu, S. K., Weavil, J. C., Mangum, T. S., and Venturelli, M. (2015). Autonomic responses to exercise: group III/IV muscle afferents and fatigue. Auton. Neurosci. 188, 19-23. doi: 10.1016/j.autneu.2014.10.018

Artioli, G. G., Gualano, B., Smith, A., Stout, J., and Lancha, A. H. Jr. (2010). Role of beta-alanine supplementation on muscle carnosine and exercise performance. Med. Sci. Sports Exerc. 42, 1162-1173. doi: 10.1249/MSS.0b013e3181c $74 \mathrm{e} 38$

Baguet, A., Reyngoudt, H., Pottier, A., Everaert, I., Callens, S., Achten, E., et al. (2009). Carnosine loading and washout in human skeletal muscles. J. Appl. Physiol. 106, 837-842. doi: 10.1152/japplphysiol.91357.2008

Bangsbo, J., Madsen, K., Kiens, B., and Richter, E. A. (1996) Effect of muscle acidity on muscle metabolism and fatigue during intense exercise in man. J. Physiol. 495(Pt 2), 587-596. doi: 10.1113/jphysiol.1996.sp021618

Bellinger, P. M., and Minahan, C. L. (2016). The effect of $\beta$-alanine supplementation on cycling time trials of different length. Eur. J. Sport Sci. 16, 829-836. doi: 10.1080/17461391.2015.1120782

Bird, S. R., Wiles, J., and Robbins, J. (1995). The effect of sodium bicarbonate ingestion on 1500-m racing time. J. Sports Sci. 13, 399-403. doi: 10.1080/02640419508732255

Boorsma, R. K., Whitfield, J., and Spriet, L. L. (2014). Beetroot juice supplementation does not improve performance of elite $1500-\mathrm{m}$ runners. Med. Sci. Sports Exerc. 46, 2326-2334. doi: 10.1249/MSS.00000000000 00364

Boyett, J. C., Giersch, G. E., Womack, C. J., Saunders, M. J., Hughey, C. A., Daley, H. M., et al. (2016). Time of day and training status both impact the efficacy of caffeine for short duration cycling performance. Nutrients 8, pii: E639. doi: 10.3390/nu8100639

Braakhuis, A. J., and Hopkins, W. G. (2015). Impact of dietary antioxidants on sport performance: a review. Sports Med. 45, 939-955. doi: $10.1007 /$ s40279-015-0323-x

Brien, D. M., and McKenzie, D. C. (1989). The effect of induced alkalosis and acidosis on plasma lactate and work output in elite oarsmen. Eur. J. Appl. Physiol. Occup. Physiol. 58, 797-802. doi: 10.1007/BF02332209

Burke, L. M., Pyne, D. B., and Telford, R. D. (1996). Effect of oral creatine supplementation on single-effort sprint performance in elite swimmers. Int. J. Sport Nutr. 6, 222-233. doi: 10.1123/ijsn.6.3.222

Burke, L. M. (2013). Practical considerations for bicarbonate loading and sports performance. Nestle Nutr. Inst. Works. Ser. 75, 15-26. doi: 10.1159/000345814 had a trivial effect on performance and weakly tended to be faster than placebo, but at present nitrate appears most relevant for non-elite athletes or athletes with modest aerobic power. Lastly beta-alanine effects on intense endurance performance was trivial. For all supplements, individualized approaches are advised since factors such as diet, gender, supplement uptake kinetics, muscle oxidative capacity and fiber distribution may impact on whether an ergogenic effect can be obtained.

\section{AUTHOR CONTRIBUTIONS}

PC and NN: Design of study, data analysis, interpretation of results, manuscript draft. YS: Data analysis, revision of manuscript. CR: Design of study, data analysis, revision of manuscript.

\section{ACKNOWLEDGMENTS}

The authors wish to thank Henriette Arnoldus for helping out retrieving manuscripts to be included in the meta-analysis.
Callahan, M. J., Parr, E. B., Hawley, J. A., and Burke, L. M. (2016). Single and combined effects of beetroot crystals and sodium bicarbonate on 4-km cycling time trial performance. Int. J. Sport Nutr. Exerc. Metab. 11, 1-23. doi: 10.1123/ijsnem.2016-0228

Carr, A. J., Hopkins, W. G., and Gore, C. J. (2011a). Effects of acute alkalosis and acidosis on performance: a meta-analysis. Sports Med. 41, 801-814. doi: 10.2165/11591440-000000000-00000

Carr, A. J., Gore, C. J., and Dawson, B. (2011b). Induced alkalosis and caffeine supplementation: effects on 2000-m rowing performance. Int. J. Sport Nutr. Exerc. Metab. 2011 21, 357-364. doi: 10.1123/ijsnem.21.5.357

Carr, A. J., Slater, G. J., Gore, C. J., Dawson, B., and Burke, L. M. (2012). Reliability and effect of sodium bicarbonate: buffering and 2000-m rowing performance. Int. J. Sports Physiol. Perform. 7, 152-160. doi: 10.1123/ijspp. 7.2 .152

Caruso, J., Charles, J., Unruh, K., Giebel, R., Learmonth, L., and Potter, W. (2012). Ergogenic effects of $\beta$-alanine and carnosine: proposed future research to quantify their efficacy. Nutrients 4, 585-601. doi: 10.3390/nu4070585

Christensen, P. M., Nyberg, M., and Bangsbo, J. (2013). Influence of nitrate supplementation on $\mathrm{VO}_{2}$ kinetics and endurance of elite cyclists. Scand. J. Med. Sci. Sports. 23, e21-e31. doi: 10.1111/sms.12005

Christensen, P. M., Petersen, M. H., Friis, S. N., and Bangsbo, J. (2014). Caffeine, but not bicarbonate, improves $6 \mathrm{~min}$ maximal performance in elite rowers. Appl. Physiol. Nutr. Metab. 39, 1058-1063. doi: 10.1139/apnm-2013-0577

Christensen, P. M., Petersen, N. K., Friis, S. N., Weitzberg, E., and Nybo, L. (2017). Effects of nitrate supplementation in trained and untrained muscle are modest with initial high plasma nitrite levels. Scand. J. Med. Sci. Sports. doi: 10.1111/sms.12848. [Epub ahead of print].

Clements, W. T., Lee, S. R., and Bloomer, R. J. (2014). Nitrate ingestion: a review of the health and physical performance effects. Nutrients 6, 5224-5264. doi: 10.3390/nu6115224

Cordingley, D. M., Bell, G. J., and Syrotuik, D. G. (2016). Caffeine alters blood potassium and catecholamine concentrations but not the perception of pain and fatigue with a $1 \mathrm{~km}$ Cycling Sprint. Int. J. Kinesiol. Sports Sci. 4, 1-9. doi: 10.7575/aiac.ijkss.v.4n.3p.1

Corn, S. D., and Barstow, T. J. (2011). Effects of oral N-acetylcysteine on fatigue, critical power, and W' in exercising humans. Respir. Physiol. Neurobiol. 178, 261-268. doi: 10.1016/j.resp.2011.06.020

Davis, J. K., and Green, J. M. (2009). Caffeine and anaerobic performance: ergogenic value and mechanisms of action. Sports Med. 39, 813-832. doi: 10.2165/11317770-000000000-00000 
De Andrade Nemezio, K. M., Bertuzzi, R., Correia-Oliveira, C. R., Gualano, B., Bishop, D. J., and Lima-Silva, A. E. (2015). Effect of creatine loading on oxygen uptake during a 1-km cycling time trial. Med. Sci. Sports Exerc. 47, 2660-2668. doi: 10.1249/MSS.0000000000000718

Derave, W., Ozdemir, M. S., Harris, R. C., Pottier, A., Reyngoudt, H., Koppo, K., et al. (2007). beta-Alanine supplementation augments muscle carnosine content and attenuates fatigue during repeated isokinetic contraction bouts in trained sprinters. J. Appl. Physiol. 103, 1736-1743. doi: 10.1152/japplphysiol.00397.2007

Derave, W., Everaert, I., Beeckman, S., and Baguet, A. (2010). Muscle carnosine metabolism and beta-alanine supplementation in relation to exercise and training. Sports Med. Mar 40, 247-263. doi: 10.2165/11530310-000000000-00000

Dodge, T. L., and Jaccard, J. J. (2006). The effect of high school sports participation on the use of performance-enhancing substances in young adulthood. J. Adolesc. Health. 39, 367-373. doi: 10.1016/j.jadohealth.2005.12.025

Doherty, M., and Smith, P. M. (2004). Effects of caffeine ingestion on exercise testing: a meta-analysis. Int. J. Sport Nutr. Exerc. Metab. 14, 626-646. doi: 10.1123/ijsnem.14.6.626

Doherty, M., Smith, P., Hughes, M., and Davison, R. (2004). Caffeine lowers perceptual response and increases power output during high-intensity cycling. J. Sports Sci. 22, 637-643. doi: 10.1080/02640410310001655741

Driller, M. W., Gregory, J. R., Williams, A. D., and Fell, J. W. (2012). The effects of serial and acute $\mathrm{NaHCO} 3$ loading in well-trained cyclists. J. Strength Cond. Res. 26, 2791-2797. doi: 10.1519/JSC.0b013e318241e18a

Duc, S., Villerius, V., Bertucci, W., and Grappe, F. (2007). Validity and reproducibility of the ErgomoPro power meter compared with the SRM and Powertap power meters. Int. J. Sports Physiol. Perform. 2, 270-281. doi: 10.1123/ijspp.2.3.270

Ducker, K. J., Dawson, B., and Wallman, K. E. (2013a). Effect of beta-alanine supplementation on 2000-m rowing-ergometer performance. Int. J. Sport Nutr. Exerc. Metab. 23, 336-343. doi: 10.1123/ijsnem.23.4.336

Ducker, K. J., Dawson, B., and Wallman, K. E. (2013b). Effect of beta-alanine supplementation on 800-m running performance. Int. J. Sport Nutr. Exerc. Metab. 23, 554-561. doi: 10.1123/ijsnem.23.6.554

Dutka, T. L., Lamboley, C. R., McKenna, M. J., Murphy, R. M., and Lamb, G. D. (2012). Effects of carnosine on contractile apparatus $\mathrm{Ca}^{2+}$ sensitivity and sarcoplasmic reticulum $\mathrm{Ca}^{2+}$ release in human skeletal muscle fibers. J Appl Physiol 112, 728-736. doi: 10.1152/japplphysiol.01331.2011

Eisenmann, J. C., Pivarnik, J. M., and Malina, R. M. (2001). Scaling peak VO2 to body mass in young male and female distance runners. J. Appl. Physiol. 90, 2172-2180.

Esfarjani, F., and Laursen, P. B. (2007). Manipulating high-intensity interval training: effects on $\mathrm{VO} 2 \mathrm{max}$, the lactate threshold and $3000 \mathrm{~m}$ running performance in moderately trained males. J. Sci. Med. Sport 10, 27-35. doi: 10.1016/j.jsams.2006.05.014

Ferguson, S. K., Hirai, D. M., Copp, S. W., Holdsworth, C. T., Allen, J. D., Jones, A. M., et al. (2013). Impact of dietary nitrate supplementation via beetroot juice on exercising muscle vascular control in rats. J. Physiol. 591, 547-557. doi: 10.1113/jphysiol.2012.243121

Ganio, M. S., Klau, J. F., Casa, D. J., Armstrong, L. E., and Maresh, C. M. (2009). Effect of caffeine on sport-specific endurance performance: a systematic review. J. Strength Cond. Res. 23, 315-324. doi: 10.1519/JSC.0b013e31818b979a

Geyer, H., Parr, M. K., Mareck, U., Reinhart, U., Schrader, Y., and Schänzer, W. (2004). Analysis of non-hormonal nutritional supplements for anabolicandrogenic steroids - results of an international study. Int. J. Sports Med. 25, 124-129. doi: 10.1055/s-2004-819955

Goldfinch, J., Mc Naughton, L., and Davies, P. (1988). Induced metabolic alkalosis and its effects on 400-m racing time. Eur. J. Appl. Physiol. Occup. Phys. 57, 45-48. doi: 10.1007/BF00691236

Graham, T. E., and Spriet, L. L. (1995). Metabolic, catecholamine, and exercise performance responses to various doses of caffeine. J. Appl. Physiol. 78, 867-874.

Graham, T. E. (2001). Caffeine and exercise: metabolism, endurance and performance. Sports Med. 31, 785-807. doi: 10.2165/00007256-200131110-00002

Higgins, J. P. T., Altman, D. G., and Sterne, J. A. C. (2011). "Chapter 8: assessing risk of bias in included studies," in Cochrane Handbook for Systematic
Reviews of Interventions Version 5.1.0 (updated March 2011), The Cochrane Collaboration, 2011, eds J. P. T. Higgins and S. Green. Available online at: www.handbook.cochrane.org

Hobson, R. M., Saunders, B., Ball, G., Harris, R. C., and Sale, C. (2012). Effects of $\beta$-alanine supplementation on exercise performance: a meta-analysis. Amino Acids 43, 25-37. doi: 10.1007/s00726-011-1200-Z

Hobson, R. M., Harris, R. C., Martin, D., Smith, P., Macklin, B., Gualano, B., et al. (2013). Effect of beta-alanine, with and without sodium bicarbonate, on 2000-m rowing performance. Int. J. Sport Nutr. Exerc. Metab. 23, 480-487. doi: 10.1123/ijsnem.23.5.480

Hobson, R. M., Harris, R. C., Martin, D., Smith, P., Macklin, B., ElliottSale, K. J., et al. (2014). Effect of sodium bicarbonate supplementation on 2000-m rowing performance. Int. J. Sports Physiol. Perform. 9, 139-144. doi: 10.1123/ijspp.2013-0086

Hoon, M. W., Johnson, N. A., Chapman, P. G., and Burke, L. M. (2013). The effect of nitrate supplementation on exercise performance in healthy individuals: a systematic review and meta-analysis. Int. J. Sport Nutr. Exerc. Metab. 23, 522-532. doi: 10.1123/ijsnem.23.5.522

Hoon, M. W., Jones, A. M., Johnson, N. A., Blackwell, J. R., Broad, E. M., Lundy, B., et al. (2014a). The effect of variable doses of inorganic nitrate-rich beetroot juice on simulated 2,000-m rowing performance in trained athletes. Int. J. Sports Physiol. Perform. 9, 615-620. doi: 10.1123/ijspp.2013-0207

Hoon, M. W., Hopkins, W. G., Jones, A. M., Martin, D. T., Halson, S. L., West, N. P., et al. (2014b). Nitrate supplementation and high-intensity performance in competitive cyclists. Appl. Physiol. Nutr. Metab. 39, 1043-1049. doi: 10.1139/apnm-2013-0574

Hopkins, W. G., Marshall, S. W., Batterham, A. M., and Hanin, J. (2009). Progressive statistics for studies in sports medicine and exercise science. Med. Sci. Sports Exerc. 41, 3-13. doi: 10.1249/MSS.0b013e31818cb278

Howe, S. T., Bellinger, P. M., Driller, M. W., Shing, C. M., and Fell, J. W. (2013). The effect of beta-alanine supplementation on isokinetic force and cycling performance in highly trained cyclists. Int. J. Sport Nutr. Exerc. Metab. 23, 562-570. doi: 10.1123/ijsnem.23.6.562

Jackman, M., Wendling, P., Friars, D., and Graham, T. E. (1996). Metabolic catecholamine, and endurance responses to caffeine during intense exercise. J. Appl. Physiol. 81, 1658-1663.

Jeukendrup, A., Saris, W. H., Brouns, F., and Kester, A. D. (1996). A new validated endurance performance test. Med. Sci. Sports Exerc. 28, 266-270. doi: 10.1097/00005768-199602000-00017

Jones, A. M. (2014). Dietary nitrate supplementation and exercise performance. Sports Med. 44(Suppl. 1), S35-S45. doi: 10.1007/s40279-014-0149-y

Jones, R. L., Stellingwerff, T., Artioli, G. G., Saunders, B., Cooper, S., and Sale, C. (2016). Dose-response of sodium bicarbonate ingestion highlights individuality in time course of blood analyte responses. Int. J. Sport. Nutr. Exerc. Metab. 26, 445-453. doi: 10.1123/ijsnem.2015-0286

Jonvik, K. L., Nyakayiru, J., Van Dijk, J. W., Wardenaar, F. C., Van Loon, L. J., and Verdijk, L. B. (2016). Habitual dietary nitrate intake in highly trained athletes. Int. J. Sport Nutr. Exerc. Metab. 21, 1-25. doi: 10.1123/ijsnem.2016-0239

Joyce, S., Minahan, C., Anderson, M., and Osborne, M. (2012). Acute and chronic loading of sodium bicarbonate in highly trained swimmers. Eur. J. Appl. Physiol. 112, 461-469. doi: 10.1007/s00421-011-1995-z

Kilding, A. E., Overton, C., and Gleave, J. (2012). Effects of caffeine, sodium bicarbonate, and their combined ingestion on high-intensity cycling performance. Int. J. Sport Nutr. Exerc. Metab. 22, 175-183. doi: 10.1123/ijsnem.22.3.175

Kindermann, W., Keul, J., and Huber, G. (1977). Physical exercise after induced alkalosis (bicarbonate or tris-buffer). Eur J Appl Physiol Occup Physiol. 37, 197-204. doi: 10.1007/BF00421775

Kirkland, A., Coleman, D., Wiles, J. D., and Hopker, J. (2008). Validity and reliability of the Ergomopro powermeter. Int J Sports Med. 29, 913-916. doi: 10.1055/s-2008-1038621

Kohen, R., Yamamoto, Y., and Cundy, K. C. (1988). Antioxidant activity of carnosine, homocarnosine, and anserine present in muscle and brain. Proc. Natl. Acad. Sci. U.S.A. 85, 3175-3179. doi: 10.1073/pnas.85. 9.3175

Kupcis, P. D., Slater, G. J., Pruscino, C. L., and Kemp, J. G. (2012). Influence of sodium bicarbonate on performance and hydration in lightweight rowing. Int. J. Sports Physiol. Perform. 7, 11-18. doi: 10.1123/ijspp.7.1.11 
Lane, S. C., Areta, J. L., Bird, S. R., Coffey, V. G., Burke, L. M., Desbrow, B., et al. (2013). Caffeine ingestion and cycling power output in a low or normal muscle glycogen state. Med. Sci. Sports Exerc. 45, 1577-1584. doi: 10.1249/MSS.0b013e31828af183

Lansley, K. E., Winyard, P. G., Bailey, S. J., Vanhatalo, A., Wilkerson, D. P., Blackwell, J. R., et al. (2011). Acute dietary nitrate supplementation improves cycling time trial performance. Med. Sci. Sports Exerc. 43, 1125-1131. doi: 10.1249/MSS.0b013e31821597b4

Larsen, F. J., Weitzberg, E., Lundberg, J. O., and Ekblom, B. (2007). Effects of dietary nitrate on oxygen cost during exercise. Acta Physiol. (Oxf). 191, 59-66. doi: 10.1111/j.1748-1716.2007.01713.x

Laursen, P. B., Francis, G. T., Abbiss, C. R., Newton, M. J., and Nosaka, K. (2007). Reliability of time-to-exhaustion versus time-trial running tests in runners. Med. Sci. Sports Exerc. 39, 1374-1379. doi: 10.1249/mss.0b013e3180 $6010 f 5$

LeCheminant, J. D., Heden, T., Smith, J., and Covington, N. K. (2009). Comparison of energy expenditure, economy, and pedometer counts between normal weight and overweight or obese women during a walking and jogging activity. Eur. J. Appl. Physiol. 106, 675-682. doi: 10.1007/s00421-009-1059-9

Lindh, A. M., Peyrebrune, M. C., Ingham, S. A., Bailey, D. M., and Folland, J. P. (2008). Sodium bicarbonate improves swimming performance. Int. J. Sports Med. 29, 519-523. doi: 10.1055/s-2007-989228

Martin, J. C., Milliken, D. L., Cobb, J. E., McFadden, K. L., and Coggan, A. R. (1998). Validation of a mathematical model for road cycling power. J. Appl. Biomech. 14, 276-291, doi: 10.1123/jab.14.3.276

Marx, J. O., Gordon, S. E., Vos, N. H., Nindl, B. C., Gómez, A. L., Volek, J. S., et al. (2002). Effect of alkalosis on plasma epinephrine responses to high intensity cycle exercise in humans. Eur. J. Appl. Physiol. 87, 72-77. doi: 10.1007/s00421-002-0591-7

Mauger, A. R., Jones, A. M., and Williams, C. A. (2010). Influence of acetaminophen on performance during time trial cycling. J. Appl. Physiol. 108, 98-104. doi: 10.1152/japplphysiol.00761.2009

McConell, G. K., Bradley, S. J., Stephens, T. J., Canny, B. J., Kingwell, B. A., and Lee-Young, R. S. (2007). Skeletal muscle nNOS mu protein content is increased by exercise training in humans. Am. J. Physiol. Regul. Integr. Comp. Physiol. 293, R821-R828. doi: 10.1152/ajpregu.00796.2006

McNaughton, L. R., and Cedaro, R. (1991). "The effects of sodium bicarbonate on rowing ergometer performance in elite rowers," in The Australian Journal of Science and Medicine in Sport (Pennant Hills: Australian Sports Medicine Federation), 66-69.

McNaughton, L. R. (1992a). Bicarbonate ingestion: effects of dosage on 60 s cycle ergometry. J. Sports Sci. 10, 415-423. doi: 10.1080/02640419208729940

McNaughton, L. R. (1992b). Sodium bicarbonate ingestion and its effects on anaerobic exercise of various durations. J. Sports Sci. 10, 425-435. doi: 10.1080/02640419208729941

McNaughton, L. R., Ford, S., and Newbold, C. (1997). Effect of sodium bicarbonate ingestion on high intensity exercise in moderately trained women. J. Strength Condition. Res. 11, 98-102.

McNaughton, L. R., Dalton, B., and Tarr, J. (1998). The effects of creatine supplementation on high-intensity exercise performance in elite performers. Eur. J. Appl. Physiol. Occup. Physiol. 78, 236-240. doi: 10.1007/s004210050413

McNaughton, L. R., Siegler, J., and Midgley, A. (2008). Ergogenic effects of sodium bicarbonate. Curr. Sports Med. Rep. 7, 230-236. doi: 10.1249/JSR.0b013e31817ef530

Miller, B., O'Connor, H., Orr, R., Ruell, P., Cheng, H. L., and Chow, C. M. (2014). Combined caffeine and carbohydrate ingestion: effects on nocturnal sleep and exercise performance in athletes. Eur. J. Appl. Physiol. 114, 2529-2537. doi: 10.1007/s00421-014-2973-Z

Miller, P., Robinson, A. L., Sparks, S. A., Bridge, C. A., Bentley, D. J., and McNaughton, L. R. (2016). The effects of novel ingestion of sodium bicarbonate on repeated sprint ability. J. Strength Cond. Res. 30, 561-568. doi: 10.1519/JSC.0000000000001126

Mohr, M., Nielsen, J. J., and Bangsbo, J. (2011). Caffeine intake improves intense intermittent exercise performance and reduces muscle interstitial potassium accumulation. J. Appl. Physiol. 111, 1372-1379. doi: 10.1152/japplphysiol.01028.2010

Mujika, I., Chatard, J. C., Lacoste, L., Barale, F., and Geyssant, A. (1996). Creatine supplementation does not improve sprint performance in competitive swimmers. Med. Sci. Sports Exerc. 28, 1435-1441. doi: 10.1097/00005768-199611000-00014

Nelson, C. R., and Fitts, R. H. (2014). Effects of low cell pH and elevated inorganic phosphate on the pCa-force relationship in single muscle fibers at near-physiological temperatures. Am. J. Physiol. Cell Physiol. 306, C670-C678. doi: 10.1152/ajpcell.00347.2013

Nielsen, H. B., Bredmose, P. P., Strømstad, M., Volianitis, S., Quistorff, B., and Secher, N. H. (2002). Bicarbonate attenuates arterial desaturation during maximal exercise in humans. J. Appl. Physiol. 93, 724-731. doi: 10.1152/japplphysiol.00398.2000

Nordsborg, N., Mohr, M., Pedersen, L. D., Nielsen, J. J., Langberg, H., and Bangsbo, J. (2003). Muscle interstitial potassium kinetics during intense exhaustive exercise: effect of previous arm exercise. Am. J. Physiol. Regul. Integr. Comp. Physiol. 285, R143-R148. doi: 10.1152/ajpregu.00029.2003

Nyberg, M., Blackwell, J. R., Damsgaard, R., Jones, A. M., Hellsten, Y., and Mortensen, S. P. (2012). Lifelong physical activity prevents an age-related reduction in arterial and skeletal muscle nitric oxide bioavailability in humans. J. Physiol. 590, 5361-5370. doi: 10.1113/jphysiol.2012. 239053

Outram, S., and Stewart, B. (2015). Doping through supplement use: a review of the available empirical data. Int. J. Sport Nutr. Exerc. Metab. 25, 54-59. doi: 10.1123/ijsnem.2013-0174

Painelli Vde, S., Roschel, H., Jesus, F. d, Sale, C., Harris, R. C., Solis, M. Y., et al. (2013). The ergogenic effect of beta-alanine combined with sodium bicarbonate on high-intensity swimming performance. Appl. Physiol. Nutr. Metab. 38, 525-532. doi: 10.1139/apnm-2012-0286

Parkhouse, W. S., McKenzie, D. C., Hochachka, P. W., and Ovalle, W. K. (1985). Buffering capacity of deproteinized human vastus lateralis muscle. J. Appl. Physiol. 58, 14-17.

Pasman, W. J., van Baak, M. A., Jeukendrup, A. E., and de Haan, A. (1995). The effect of different dosages of caffeine on endurance performance time. Int. J. Sports Med. 16, 225-230. doi: 10.1055/s-2007-972996

Pavlov, A. R., Revina, A. A., and Dupin, A. M. (1993). The mechanism of interaction of carnosine with superoxide radicals in water solutions. Biochim. Biophys. Acta 1157, 304-312. doi: 10.1016/0304-4165(93)90114-N

Peacock, O., Tjønna, A. E., James, P., Wisløff, U., Welde, B., Böhlke, N., et al. (2012). Dietary nitrate does not enhance running performance in elite cross-country skiers. Med. Sci. Sports Exerc. 44, 2213-2219. doi: 10.1249/MSS.0b013e3182640f48

Peart, D. J., Siegler, J. C., and Vince, R. V. (2012). Practical recommendations for coaches and athletes: a meta-analysis of sodium bicarbonate use for athletic performance. J. Strength Cond. Res. 26, 1975-1983. doi: 10.1519/JSC.0b013e3182576f3d

Peeling, P., Cox, G. R., Bullock, N., and Burke, L. M. (2015). Beetroot Juice Improves On-Water $500 \mathrm{M}$ Time-Trial Performance, and Laboratory-Based Paddling Economy in National and International-Level Kayak Athletes. Int. J. Sport Nutr. Exerc. Metab. 25, 278-284. doi: 10.1123/ijsnem.20 14-0110

Pierce, E. F., Eastman, N. W., Hammer, W. H., and Lynn, T. D. (1992). Effect of induced alkalosis on swimming time trials. J. Sports Sci. 10, 255-259. doi: 10.1080/02640419208729924

Porcelli, S., Ramaglia, M., Bellistri, G., Pavei, G., Pugliese, L., Montorsi, M., et al. (2015). Aerobic fitness affects the exercise performance responses to nitrate supplementation. Med. Sci. Sports Exerc. 47, 1643-1651. doi: 10.1249/MSS.0000000000000577

Pruscino, C. L., Ross, M. L., Gregory, J. R., Savage, B., and Flanagan, T. R. (2008) Effects of sodium bicarbonate, caffeine, and their combination on repeated 200-m freestyle performance. Int. J. Sport Nutr. Exerc. Metab. 18, 116-130. doi: 10.1123/ijsnem.18.2.116

Quesnele, J. J., Laframboise, M. A., Wong, J. J., Kim, P., and Wells, G. D. (2014). The effects of beta-alanine supplementation on performance: a systematic review of the literature. Int. J. Sport Nutr. Exerc. Metab. 24, 14-27. doi: 10.1123/ijsnem.2013-0007

Raymer, G. H., Marsh, G. D., Kowalchuk, J. M., and Thompson, R. T. (2004). Metabolic effects of induced alkalosis during progressive forearm exercise to fatigue. J. Appl. Physiol. 96, 2050-2056. doi: 10.1152/japplphysiol.01261.2003

R Core Team (2016). R: A Language and Environment for Statistical Computing. Vienna: R Foundation for Statistical Computing. 
Requena, B., Zabala, M., Padial, P., and Feriche, B. (2005). Sodium bicarbonate and sodium citrate: ergogenic aids? J. Strength Cond. Res. 19, 213-224. doi: 10.1519/00124278-200502000-00036

Rossiter, H. B., Cannell, E. R., and Jakeman, P. M. (1996). The effect of oral creatine supplementation on the 1000 -m performance of competitive rowers. J. Sports Sci. 14, 175-179. doi: 10.1080/02640419608727699

Santos Rde, A., Kiss, M. A., Silva-Cavalcante, M. D., Correia-Oliveira, C. R., Bertuzzi, R., Bishop, D. J., et al. (2013). Caffeine alters anaerobic distribution and pacing during a 4000-m cycling time trial. PLoS ONE 8:E75399. doi: 10.1371 /journal.pone.0075399

Saunders, B., Sale, C., Harris, R. C., and Sunderland, C. (2014). Sodium bicarbonate and high-intensity-cycling capacity: variability in responses. Int. J. Sports Physiol. Perform. 9, 627-632. doi: 10.1123/ijspp.2013-0295

Saunders, B., Elliott-Sale, K., Artioli, G. G., Swinton, P. A., Dolan, E., Roschel, H., et al. (2017). $\beta$-alanine supplementation to improve exercise capacity and performance: a systematic review and meta-analysis. Br. J. Sports Med. 51, 658-669. doi: 10.1136/bjsports-2016-096396

Schubert, M. M., and Astorino, T. A. (2013). A systematic review of the efficacy of ergogenic aids for improving running performance. J. Strength Cond. Res. 27, 1699-1707. doi: 10.1519/JSC.0b013e31826cad24

Siegler, J. C., Midgley, A. W., Polman, R. C., and Lever, R. (2010). Effects of various sodium bicarbonate loading protocols on the time-dependent extracellular buffering profile. J. Strength Cond. Res. 24, 2551-2557. doi: 10.1519/JSC.0b013e3181aeb154

Siegler, J. C., Marshall, P. W., Bray, J., and Towlson, C. (2012). Sodium bicarbonate supplementation and ingestion timing: does it matter? J. Strength Cond. Res. 26, 1953-1958. doi: 10.1519/JSC.0b013e3182392960

Skinner, T. L., Jenkins, D. G., Coombes, J. S., Taaffe, D. R., and Leveritt, M. D. (2010). Dose response of caffeine on 2000-m rowing performance. Med. Sci. Sports Exerc. 42, 571-576. doi: 10.1249/MSS.0b013e3181b6668b

Slattery, K. M., Dascombe, B., Wallace, L. K., Bentley, D. J., and Coutts, A. J. (2014). Effect of $\mathrm{N}$-acetylcysteine on cycling performance after intensified training. Med. Sci. Sports Exerc. 46, 1114-1123. doi: 10.1249/MSS.0000000000000222

Solheim, S. A., Nordsborg, N. B., Ritz, C., Berget, J., Kristensen, A. H., and Mørkeberg, J. (2016). Use of nutritional supplements by Danish elite athletes and fitness customers. Scand. J. Med. Sci. Sports. doi: 10.1111/sms.12704. [Epub ahead of print].

Spriet, L. L. (2014). Exercise and sport performance with low doses of caffeine. Sports Med. 44(Suppl. 2), S175-S184. doi: 10.1007/s40279-014-0257-8

Stellingwerff, T., Boit, M. K., Res, P. T., and International Association of Athletics Federations (2007). Nutritional strategies to optimize training and racing in middle-distance athletes. J. Sports Sci. 25(Suppl 1.), S17-S28. Review. Erratum in J. Sports Sci. 2009 27:667 doi: 10.1080/02640410701607213

Street, D., Nielsen, J. J., Bangsbo, J., and Juel, C. (2005). Metabolic alkalosis reduces exercise-induced acidosis and potassium accumulation in human skeletal muscle interstitium. J. Physiol. 566, 481-489. doi: 10.1113/jphysiol.2005.086801

Syrotuik, D. G., Game, A. B., Gillies, E. M., and Bell, G. J. (2001). Effects of creatine monohydrate supplementation during combined strength and high intensity rowing training on performance. Can. J. Appl. Physiol. 26, 527-542. doi: 10.1139/h01-029

Thomas, C., Delfour-Peyrethon, R., Bishop, D. J., Perrey, S., Leprêtre, P. M., Dorel, S., et al. (2016). Effects of pre-exercise alkalosis on the decrease in VO2 at the end of all-out exercise. Eur. J. Appl. Physiol. 116, 85-95. doi: 10.1007/s00421-015-3239-0

Tiryaki, G. R., and Atterbom, H. A. (1995). The effects of sodium bicarbonate and sodium citrate on $600 \mathrm{~m}$ running time of trained females. J. Sports Med. Phys. Fitness 35, 194-198.

Tønnessen, E., Svendsen, I. S., Olsen, I. C., Guttormsen, A., and Haugen, T. (2015). Performance development in adolescent track and field athletes according to age, sex and sport discipline. PLoS ONE. 10:e129014. doi: 10.1371/journal.pone.0129014

Trexler, E. T., Smith-Ryan, A. E., Stout, J. R., Hoffman, J. R., Wilborn, C. D., Sale, C., et al. (2015). International society of sports nutrition position stand: beta-Alanine. J. Int. Soc. Sports Nutr. 12:30. doi: 10.1186/s12970-0150090-y

Tscholl, P., Alonso, J. M., Dollé, G., Junge, A., and Dvorak, J. (2010). The use of drugs and nutritional supplements in top-level track and field athletes. Am. J. Sports Med. 38, 133-140. doi: 10.1177/0363546509 344071

Tsitsimpikou, C., Tsiokanos, A., Tsarouhas, K., Schamasch, P., Fitch, K. D., Valasiadis, D., et al. (2009). Medication use by athletes at the Athens 2004 Summer Olympic Games. Clin. J. Sport Med. 19, 33-38. doi: 10.1097/JSM.0b013e31818f169e

Vanhatalo, A., McNaughton, L. R., Siegler, J., and Jones, A. M. (2010a). Effect of induced alkalosis on the power-duration relationship of "all-out" exercise. Med. Sci. Sports Exerc. 42, 563-570. doi: 10.1249/MSS.0b013e3181b $71 \mathrm{a} 4 \mathrm{a}$

Vanhatalo, A., Bailey, S. J., Blackwell, J. R., DiMenna, F. J., Pavey, T. G., Wilkerson, D. P., et al. (2010b). Acute and chronic effects of dietary nitrate supplementation on blood pressure and the physiological responses to moderate-intensity and incremental exercise. Am. J. Physiol. Regul. Integr. Comp. Physiol. 299, R1121-R1131. doi: 10.1152/ajpregu.0020 6.2010

van Houwelingen, H. C., Arends, L. R., and Stijnen, T. (2002). Advanced methods in meta-analysis: multivariate approach and meta-regression. Stat Med. Feb 21, 589-624. doi: 10.1002/sim.1040

Viechtbauer, W. (2010). Conducting meta-analyses in R with the metafor package. J. Stat. Soft. 36, 1-48. doi: 10.18637/jss.v036.i,03

WADA (2015). World Anti-Doping Agency Online Publication, October 2016. Available online at: https://wada-mailing-list.s3.amazonaws.com/WADA2015-Monitoring-Program-Figures.pdf

Wiles, J. D., Bird, S. R., Hopkins, J., and Riley, M. (1992). Effect of caffeinated coffee on running speed, respiratory factors, blood lactate and perceived exertion during 1500-m treadmill running. Br. J. Sports Med. 26, 116-120. doi: $10.1136 /$ bjsm.26.2.116

Wiles, J. D., Coleman, D., Tegerdine, M., and Swaine, I. L. (2006). The effects of caffeine ingestion on performance time, speed and power during a laboratory-based $1 \mathrm{~km}$ cycling time-trial. J. Sports Sci. 24, 1165-1171. doi: 10.1080/02640410500457687

Wilkerson, D. P., Hayward, G. M., Bailey, S. J., Vanhatalo, A., Blackwell, J. R., and Jones, A. M. (2012). Influence of acute dietary nitrate supplementation on 50 mile time trial performance in well-trained cyclists. Eur. J. Appl. Physiol. 112, 4127-4134. doi: 10.1007/s00421-012-2397-6

Wilkes, D., Gledhill, N., and Smyth, R. (1983). Effect of acute induced metabolic alkalosis on 800-m racing time. Med. Sci. Sports Exerc. 15, 277-280. doi: 10.1249/00005768-198315040-00004

Wylie, L. J., Kelly, J., Bailey, S. J., Blackwell, J. R., Skiba, P. F., Winyard, P. G., et al. (2013). Beetroot juice and exercise: pharmacodynamic and dose-response relationships. J. Appl. Physiol. 115, 325-336. doi: 10.1152/japplphysiol.00372.2013

Young, K. C., Kendall, K. L., Patterson, K. M., Pandya, P. D., Fairman, C. M., and Smith, S. W. (2014). Rowing performance, body composition, and bone mineral density outcomes in college-level rowers after a season of concurrent training. Int. J. Sports Physiol. Perform. 9, 966-972. doi: 10.1123/ijspp.201 3-0428

Conflict of Interest Statement: The authors declare that the research was conducted in the absence of any commercial or financial relationships that could be construed as a potential conflict of interest.

Copyright (c) 2017 Christensen, Shirai, Ritz and Nordsborg. This is an open-access article distributed under the terms of the Creative Commons Attribution License (CC $B Y)$. The use, distribution or reproduction in other forums is permitted, provided the original author(s) or licensor are credited and that the original publication in this journal is cited, in accordance with accepted academic practice. No use, distribution or reproduction is permitted which does not comply with these terms. 